\title{
Fast Reactor Alternative Studies: Effects of Transuranic Groupings on Metal and Oxide Sodium Fast Reactor Designs
}

R. M. Ferrer

M. Asgari

S. E. Bays

B. Forget

September 2007

The INL is a U.S. Department of Energy National Laboratory operated by Battelle Energy Alliance

Idaho National Laboratory 
INL/EXT-07-13236

\title{
Fast Reactor Alternative Studies: Effects of Transuranic Groupings on Metal and Oxide Sodium Fast Reactor Designs
}

\author{
R. M. Ferrer \\ M. Asgari \\ S. E. Bays \\ B. Forget
}

September 2007

Idaho National Laboratory
Idaho Falls, Idaho 83415

Prepared for the

U.S. Department of Energy

Office of Nuclear Energy

Under DOE Idaho Operations Office

Contract DE-AC07-05ID14517 


\section{Fast Reactor Alternative Studies: Effects of Transuranic Groupings on Metal and Oxide Sodium Fast Reactor Designs}

INL/EXT-07-13236

September 2007

Approved by

Rodolfo M. Ferrer, Principal Author

Date

David Nigg, Reactor and Nuclear Physics

Date

Department Manager

Kathryn McCarthy, Systems Analysis Campaign

Date

Director 


\section{ABSTRACT}

A 1000 MWth commercial-scale Sodium Fast Reactor (SFR) design with a conversion ratio (CR) of 0.50 was selected in this study to perform perturbations on the external feed coming from Light Water Reactor Spent Nuclear Fuel (LWR SNF) and separation groupings in the reprocessing scheme. A secondary SFR design with a higher conversion ratio $(\mathrm{CR}=0.75)$ was also analyzed as a possible alternative, although no perturbations were applied to this model.

Metal and oxide fuel SFR designs were both included in the analysis. Initial results showed good agreement between the UREX +1 a base cases and data previously published in the literature for the SFR conceptual design. The initial set of perturbations involved varying the external feed to study the so-called 'vintage problem', which addresses the large variation in burnup and cooling needed to be accommodated in the SFR. Three sets of external feed isotopic vectors were generated for the cases of a low burnup and long cooling time ( $33 \mathrm{MWd} / \mathrm{kg}$, 30 year cooled LWR SNF), high burnup and medium cooling time (51 $\mathrm{MWd} / \mathrm{kg}, 10$ year cooled LWR SNF), and the reference high burnup and short cooling time (51 MWd/kg, 5 year cooled LWR SNF.) Results show that the choice of external feed has little impact on the TRU enrichment, burnup, or cycle length of either the metal or oxide fuel SFR because all the TRU vectors having similar fissile plutonium content. Also, the slightly larger presence of americium in the low burnup, long cooling time vector increases its consumption rate in the SFR, and thus increases the production of curium 242 and 244 compared to a high burnup, short cooling time TRU vector.

The second set of perturbations involved varying the external feed and reprocessing of the TRU groupings for the metal and oxide SFR designs. Four separation technologies were applied to the LWR SNF; PUREX, UREX+2/+3, UREX+4, and UREX+1a. In the case of metal fuel, this perturbation only affects the feed of isotopes coming from the separation facility, while the electrochemical reprocessing recycles all TRU isotopes from the SFR back into the reactor core as fuel. This is different from the oxide case, in which the four separation technologies (PUREX and UREX+) may also be applied to the reprocessing of the SFR fuel. In the case of PUREX, for example, the neptunium, americium, curium, berkelium, and californium are separated from the discharged fuel reprocessing and assumed to be disposed of, thus creating fresh plutonium-only oxide fuel.

The effects of the choice of separation and reprocessing strategy on the neutron emission, gamma energy, and decay heat at beginning-of-equilibrium cycle (BOEC) and the decay heat at end-ofequilibrium cycle (EOEC) were also incorporated into this study. The effects of different 'groupings' were found to have a minimal effect on the parameters mentioned above for the metal fuel SFR, since all TRU isotopes are homogeneously recycled back into the core. In the case of an oxide fuel SFR, the BOEC charge neutron emission, gamma energy, and decay heat all decrease as neptunium, americium, curium, and the higher mass actinides are assumed to be selectively separated, depending from the process, from discharge and stored elsewhere. A comparison of the decay heat per subassembly is performed from the time of discharge out to 20 years after discharge.

Finally, additional perturbations on various SFR startup scenarios were also analyzed. The analysis looked into four initial external feeds that were deemed most likely to be used to start the SFR: $\mathrm{Pu}$ from spent nuclear fuel, $\mathrm{Np}-\mathrm{Pu}$ from spent nuclear fuel, weapons grade $\mathrm{Pu}$ and enriched uranium. 


\section{DISCLAIMER}

This report was prepared as an account of work sponsored by an agency of the United States Government. Neither the United States Government nor any agency thereof, or any of their employees, makes any warranty, express or implied, or assumes any legal liability or responsibility for the accuracy, completeness, or usefulness of any information, apparatus, product, or process disclosed, or represents that its use would not infringe privately owned rights. Reference herein to any specific commercial product, process, or service by trade name, trademark, manufacturer, or otherwise, does not necessarily constitute or imply its enforcement, recommendation, or favoring by the United States Government or any agency thereof. The views and opinions of authors expressed herein do not necessarily state or reflect those of the United States Government or any agency thereof. 


\section{ACKNOWLEDGEMENTS}

The authors would like to thank Steve Piet (INL) and Michael Todosow (BNL) for their contributions. 


\section{CONTENTS}

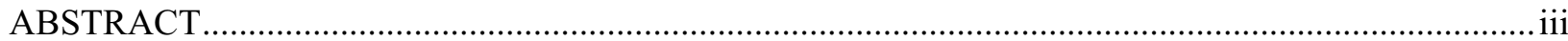

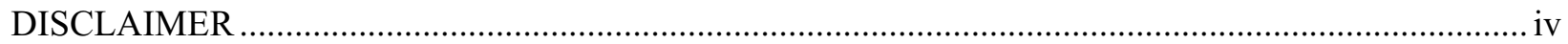

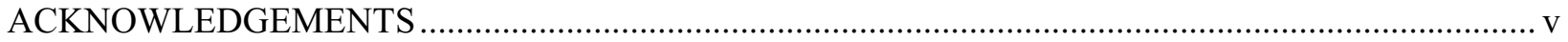

GLOSSARY, ACRONYMS, AND ABBREVIATIONS …................................................................

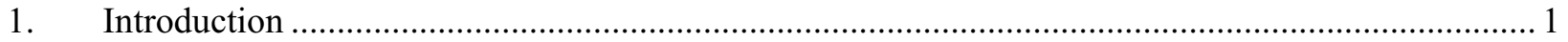

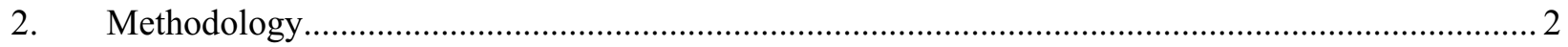

2.1 Reactor Physics, Fuel Cycle and Displacements-Per-Atom Calculations .......................... 2

2.2 Neutron Emission, Gamma Energy and Decay Heat Calculations.................................... 2

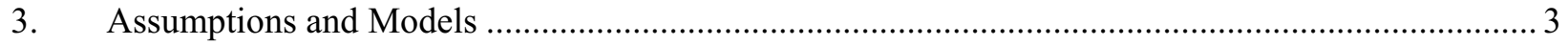

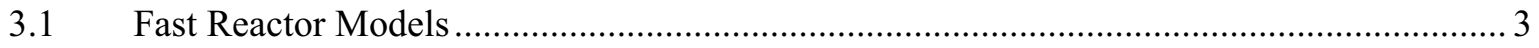

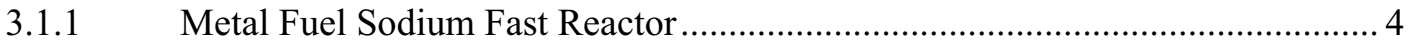

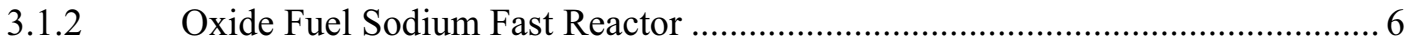

3.2 External Fuel Cycle Models .................................................................................. 6

3.2.1 Alternate Metal Fuel SFR External Fuel Cycles .......................................... 7

3.2.2 Alternate Oxide Fuel SFR External Fuel Cycles.............................................. 8

3.3 Light Water Reactor Spent Nuclear Fuel External Feeds................................................. 8

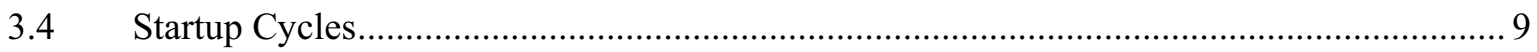

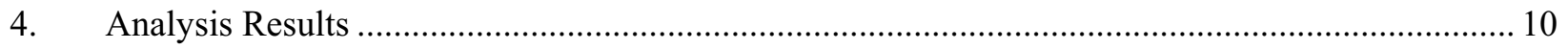

4.1 Reactor Physics, Fuel Cycle and Displacements-Per-Atom Calculations .......................... 10

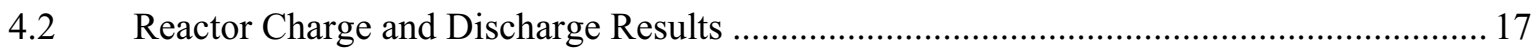

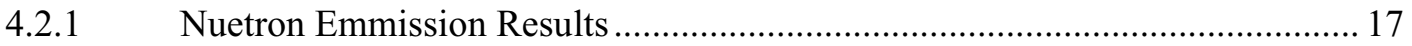

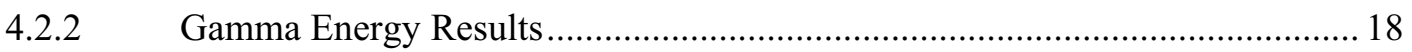

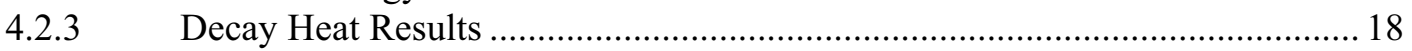

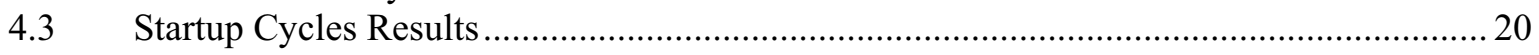

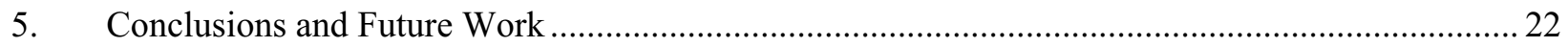

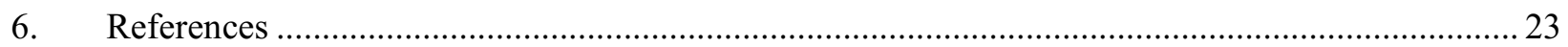




\section{FIGURES}

Figure 3-1 One Third Symmetric Radial Layout of Metal Fuel CR=0.50 SFR Design..................... 5

Figure 3-2 One Third Symmetric Radial Layout of Metal Fuel CR=0.75 SFR Design..................... 5

Figure 3-3 One Third Symmetric Radial Layout of Oxide Fuel CR=0.50, 0.75 SFR Design............. 6

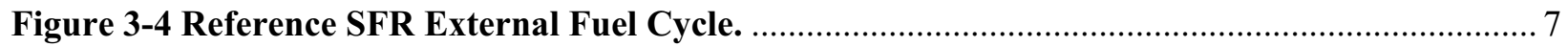

Figure 4-1 Average Charge Gamma Energy for SFR and Thermal Recycling with Multiple

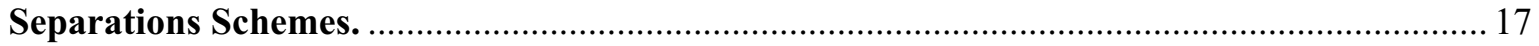

Figure 4-2 Average Charge Gamma Energy for SFR and Thermal Recycling with Multiple

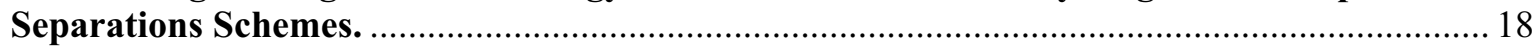

Figure 4-3 Average Charge Decay Heat per kg of TRU For SFR and Thermal Recycling with

Multiple Separations Schemes. 


\section{TABLES}

Table 3-1 Fuel Assembly Design for Metal and Oxide Fuel CR=0.50, 0.75 SFR. ........................... 4

Table 3-2 Aqueous Separation Processes and Relationship to Transuranic Groupings................... 7

Table 3-3 External TRU Isotopic Feed Vectors in Weight Percent for Multiple LWR SNF

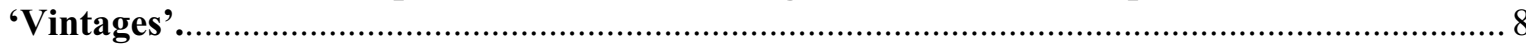

Table 4-1 Fuel Cycle Results for Metal CR=0.50 SFR Design for Multiple Separation Processes and

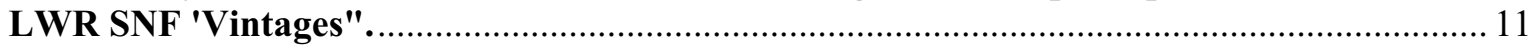

Table 4-2 Fuel Cycle Results for Oxide CR=0.50 SFR Design for Multiple Separation Processes and

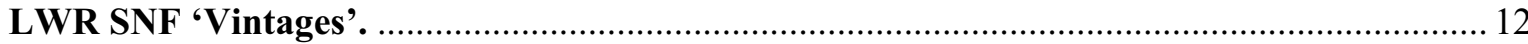

Table 4-3 Fuel Cycle Results for Metal and Oxide CR=0.75 SFR Design for Reference UREX+1a

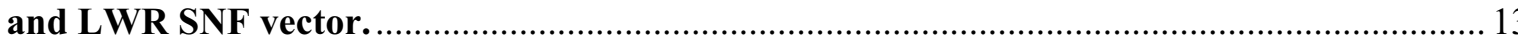

Table 4-4 Consumption Rates (kg/EFPY) for Metal CR=0.50 SFR Design for Multiple Separation

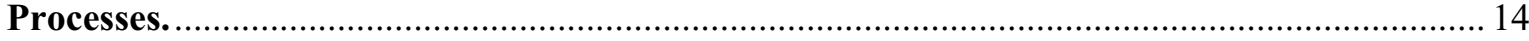

Table 4-5 Consumption Rates (kg/EFPY) for Oxide CR=0.50 SFR Design for Multiple Separation

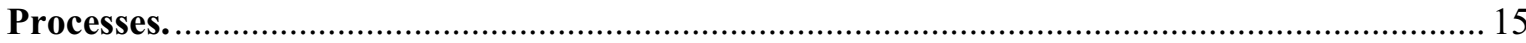

Table 4-6 Comparison of Consumption Rates (kg/EFPY) Between Metal and Oxide CR=0.50 SFR Design for 'Young' and 'Old' LWR SNF Vintages.

Table 4-7 Average Charge and Discharge Decay Heat for Metal and Oxide CR=0.50 SFR Design for Multiple Separation Processes.

Table 4-8 Average Charge and Discharge Decay Heat for Metal and Oxide $C R=0.50$ SFR Design

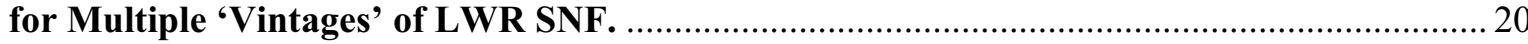

Table 4-9 Cycle Performance Parameters for Startup Cases. 20 


\title{
GLOSSARY, ACRONYMS, AND ABBREVIATIONS
}

\author{
ANL Argonne National Laboratory \\ DOE Department of Energy \\ GNEP Global Nuclear Energy Partnership \\ INL Idaho National Laboratory \\ LWR Light Water Reactor \\ MA Minor Actinides \\ $\mathrm{MC}^{2}-2 \quad$ Code System for Calculating Fast Neutron Spectra and Multigroup Cross- \\ Sections \\ ORNL Oak Ridge National Laboratory \\ REBUS-3 Code System for Analysis of Fast Reactor Fuel Cycles \\ RSICC Radiation Safety Information Computational Center \\ SFR Sodium Fast Reactor \\ S-PRISM SuperPRISM Advanced Fast Reactor \\ SNF Spent Nuclear Fuel \\ TRU Transuranics \\ UREX Uranium Extraction Process
}




\section{Introduction}

The Global Nuclear Energy Partnership (GNEP) is currently studying the deployment of Sodium Fast Reactors (SFRs), which will be used to burn the long-lived radioisotopes in a fast spectrum. In the current 'snapshot' of this SFR system, two sets of designs are currently being evaluated for the homogeneous recycling of TRU; a metal fuel fast reactor with electrochemical reprocessing and an oxide fuel fast reactor with aqueous separation for reprocessing.

Even in an SFR, however, not all TRU can fission with the same efficiency. Higher mass actinides such as curium are produced in a transuranic-burning reactor more readily than past fast reactor fuel cycles because of the fertile americium concentration in LWR SNF. This has a significant impact on the decay heat during the fuel reprocessing and re-fabrication. Furthermore, the threshold fission for most actinides occurs at very high energies, higher than the average neutron energy in a fast reactor energy spectrum. Thus, homogeneous recycling does not necessarily results in the complete destruction of minor actinides (MA), but in the stabilization of the amount of MA in the nuclear enterprise that would otherwise be destined to geologic repository disposal.

The purpose of this study is to quantity the effects that different LWR SNF 'vintages' and reprocessing strategies will have on the reactor physics and fuel cycle parameters for the SFR design in question. Also, the neutron emission, gamma energy, and decay heat for the equilibrium charge and the decay heat from discharge out to 20 years is calculated and compared between different separation strategies. Additionally, different SFR startup scenarios were analyzed to look into the possibility of starting the reactor without necessarily having the reprocessing facility completed.

The metal and oxide fuel SFR prototypes used in this study are SuperPRISM-based (Ref. 3) design variations for which the conversion ratio (CR) has been decreased from breakeven to 0.50 through fuel pin diameter reduction. Previous studies involving the reduction of the conversion ratio in fast reactors typically involved flattening (Ref. 4 \&5) (geometric spoiling), the reduction of the fuel pin diameter (Ref. 6) or a combination of both (Ref. 7.)

The results from a metal and oxide $\mathrm{CR}=0.75$ SFR design are also presented, though no perturbations were performed in this specific case. The rest of this report is organized in the following manner: Section II describes the methodology used in the fuel cycle analysis, Section III presents the assumptions made and the reactor models used, and Section IV presents the results from the analyses. Finally, conclusions and recommendations for future work are presented in Section V. 


\section{Methodology}

\subsection{Reactor Physics, Fuel Cycle and Displacements-Per-Atom Calculations}

The Argonne National Laboratory (ANL) fast reactor codes $\mathrm{MC}^{2}-2$ (Ref. 8) and REBUS-3 (Ref. 9) were used to generate multi-group fast spectrum cross-sections and to perform fuel cycle calculations. The $\mathrm{MC}^{2}-2$ code was used to generate 33 energy-group cross section sets (group constants) for each of the fuel enrichment zones, reflectors and shields. Starting with an ultra-fine group ENDF/B-V cross section library, $\mathrm{MC}^{2}-2$ creates collapsed cross section sets by performing a critical buckling search. While this approach does not account for spatial variations within or between the various core regions, it has been proven to be sufficient for fast reactor scoping calculations. The accurate treatment of resolved and unresolved resonance self-shielding at operating temperature is of particular importance in this procedure. These cross section sets are subsequently concatenated into a single data file so that they may be used by the fuel cycle code REBUS-3 to perform an enrichment search for an equilibrated fuel cycle given userdefined constraints (such as burnup limit).

The REBUS-3 nodal diffusion option in hexagonal-z geometry was used to perform the flux calculations. In our fuel cycle model individual fuel assemblies within a region (enrichment region) are homogenized utilizing representative neutron spectra. Therefore, independent batches of fuel are tracked within the external fuel cycle but not explicitly spatially represented in the physics calculation. Furthermore, the constraints in the equilibrium calculations involved a search of the specific fresh fuel charge enrichment given a discharge burnup limit. This was done by first estimating the initial fuel composition by assuming a certain approximate enrichment. The fuel cycle code searches for an enrichment that does not violate the maximum burnup limit for the uncontrolled core (the multiplication factor equal to 1.0000 at end-of-life). An automated scripting system is used to re-calculate the crosssections for each enrichment zone based on that zone's fuel inventory at equilibrium. This ensures that the group constants correspond to the equilibrium case (since the initial cross section set is based only on an estimate of the actual TRU enrichment). Since REBUS-3 only deals with the closed portion of the fuel cycle, the externally supplied feed is made sufficiently large to provide the reprocessing with enough heavy metal to constitute the next batch of fresh fuel.

The corrected charge enrichment and equilibrium cycle length is reported. The peak fast flux was used to calculate the peak fast fluence and a limit of $4.0 \times 10^{23} \mathrm{n} / \mathrm{cm}^{2}$ for HT9 cladding and structure is assumed to be the fluence limit (Ref. 10-12.) This material limit was verified by performing subsequent displacements-per-atom (DPA) calculations and verifying that it remained below the 200 DPA limit. In order to calculate the maximum displacements-per-atom (DPA) occurring in the HT9 cladding and structure, DPA cross-sections were obtained from NJOY (Ref. 13) using a 33 energy-group structure characteristic of a fast neutron spectrum for the SFR.

\subsection{Neutron Emission, Gamma Energy and Decay Heat Calculations}

Finally, the SCALE 5.1 code package (Ref. 14) was used to generate LWR SNF feeds for the SFR. The lattice physics code TRITON (Ref. 15) was used to model fuel being burned in an LWR and ORIGEN-S (Ref. 16) was used to predict the concentration of isotopes after cooling and storage. SCALE 5.1 was also used to calculate the neutron emission, gamma energy, and decay heat for the beginning-ofequilibrium cycle (BOEC) mass charge reported by REBUS-3 and was normalized on a per kg-TRU basis. Furthermore, ORIGEN-S was used to perform a decay heat calculation of the discharge from the moment it exits the core out to 20 years in the future. This latter calculation was normalized on a subassembly level. 


\section{Assumptions and Models}

In this section the SFR models and their corresponding external fuel cycle are discussed. Detailed thermal-hydraulics and material considerations, such as linear power limits and thermal conductivity models for the metal and oxide fuels, are discussed in details in Reference 6. As discussed in Section I, the methodology applied to the variation of the conversion ratio involved a reduction in pin diameter, which effectively reduces the fuel volume fraction. This causes the TRU enrichment to increase and consequently the conversion ratio to decrease for the same fuel cycle. Once again, detailed descriptions of this process and its effects on the thermal performance of the assembly design are available in Reference 6. One final important aspect to consider is the isotopes tracked in the transmutation chain. Traditionally, fast reactor fuel cycle depletion calculations only tracked isotopes in the minor actinide chain up to $\mathrm{Cm}$ 246. The rationale behind this practice was that the concentration of higher curium, berkelium, and californium is very small and has negligible impact in reactor physics and fuel cycle considerations. While this is correct, small amounts of the higher curium, berkelium and californium can have considerable impact on the neutron emission of the reactor charge and discharge, and therefore impact fuel handling, repository performance, VISION scenario studies, etc. The importance of these higher mass actinides is shown in Reference 17 (in press). Consequently, all higher mass actinides are tracked in the SFR models presented in this report.

\subsection{Fast Reactor Models}

The strategy followed in the reduction of the conversion ratio of the SFR models from the original S-PRISM designs was to reduce the fuel pin diameter in the fuel assemblies. The choice of metal and oxide SFR designs with $\mathrm{CR}=0.50,0.75$ represented a modest compromise between the needs to burn TRU and the material irradiation experience from past test programs (Ref. 10-12.)

The fuel assembly cold dimensions, along with the fuel pin design and volume fractions for the reference metal and oxide SFRs, are listed in Table 3.1. The original S-PRISM assembly design had 271 pins per assembly, while the assembly designs for the metal and oxide $\mathrm{CR}=0.50 \mathrm{SFR}$ has 324 pins per assembly. The reduced thermal conductivity and/or fuel solidus temperature of higher TRU enriched fuel pins required a larger number of pins per assembly in order to reduce the average linear power to an acceptable limit. The shrinking of the fuel pin diameter also entails using spacer grids instead of wire wrap in the assembly design, thus the difference between the $\mathrm{CR}=0.50$ (higher TRU enrichment) and 0.75 (lower TRU enrichment). Also worth noting is the axial heights of the designs. The axial dimension of oxide core is $35 \%$ taller than the metal core. This is due to the lower mass density of oxide fuel and thus the need to increase the fuel volume in order to accommodate comparable amounts of TRU to the metal fuel case.

The detailed design and geometry of the control rod mechanism, reflector, shield, and gas expansion modules (GEMs) can be found in another report (Ref. 6.) It suffices to say that these are modeled as homogenous regions and are very similar to those proposed for the S-PRISM design. 
Table 3-1 Fuel Assembly Design for Metal and Oxide Fuel CR=0.50, 0.75 SFR.

\begin{tabular}{|c|c|c|c|c|}
\hline & \multicolumn{2}{|c|}{ Metal } & \multicolumn{2}{|c|}{ Oxide } \\
\hline & $\mathrm{CR}=0.50$ & $\mathrm{CR}=0.75$ & $\mathrm{CR}=0.50$ & $\mathrm{CR}=0.75$ \\
\hline Assembly pitch, cm & 16.142 & 16.142 & 16.142 & 16.142 \\
\hline $\begin{array}{c}\text { Inter-assembly gap, } \\
\mathrm{cm}\end{array}$ & 0.432 & 0.432 & 0.432 & 0.432 \\
\hline $\begin{array}{l}\text { Duct outside flat-to- } \\
\text { flat, cm }\end{array}$ & 15.710 & 15.710 & 15.710 & 15.710 \\
\hline Duct material & HT9 & HT9 & HT9 & HT9 \\
\hline Duct thickness & 0.394 & 0.394 & 0.394 & 0.394 \\
\hline $\begin{array}{c}\text { Fuel Pins per } \\
\text { Assembly }\end{array}$ & 324 & 271 & 324 & 271 \\
\hline Spacer Type & Grid & Wire & Grid & Wire \\
\hline Bond & $\mathrm{Na}$ & $\mathrm{Na}$ & $\mathrm{He}$ & $\mathrm{He}$ \\
\hline Core Height, $\mathrm{cm}$ & 101.60 & 101.60 & 137.16 & 137.16 \\
\hline Plenum Height, cm & 191.14 & 191.14 & 170.82 & 170.82 \\
\hline $\begin{array}{c}\text { Overall Pin Length, } \\
\mathrm{cm}\end{array}$ & 407.04 & 407.04 & 422.28 & 422.28 \\
\hline $\begin{array}{c}\text { Fuel Smeared/ } \\
\text { Fabrication Density, } \\
\% \text { TD }\end{array}$ & $75 / 100$ & $75 / 100$ & $85 / 89.4$ & $85 / 89.4$ \\
\hline Pin Diameter, cm & 0.623 & 0.755 & 0.658 & 0.808 \\
\hline $\begin{array}{l}\text { Cladding Thickness, } \\
\mathrm{cm}\end{array}$ & 0.0559 & 0.0559 & 0.0635 & 0.0635 \\
\hline $\begin{array}{l}\text { Wire Wrap Diameter, } \\
\mathrm{cm}\end{array}$ & N/A & 0.1329 & N/A & 0.0797 \\
\hline $\begin{array}{l}\text { Pin Pitch-to-diameter } \\
\text { Ratio }\end{array}$ & 1.293 & 1.176 & 1.224 & 1.099 \\
\hline Vol. Fractions, \%: & & & & \\
\hline Fuel & 22.08 & 29.30 & 30.22 & 41.65 \\
\hline Bond & 7.36 & 9.77 & 1.56 & 2.16 \\
\hline Structure & 26.41 & 25.68 & 29.22 & 27.71 \\
\hline Coolant & 44.15 & 35.25 & 39.00 & 28.48 \\
\hline
\end{tabular}

\subsubsection{Metal Fuel Sodium Fast Reactor}

The radial layout of the metal $\mathrm{CR}=0.50 \mathrm{SFR}$ core consists of three driver fuel regions; the inner, middle, and outer core. A schematic of this layout is shown below in Figure 3.1. The inner core consists of four rows containing a total of 42 assemblies. The middle core consists of two rows containing a total of 66 assemblies with a charge TRU enrichment of 1.25 times that of the inner core. Finally, the outer core consists of a single row containing 36 assemblies with a charge TRU enrichment of 1.50 times that of the inner core. Such an enrichment splitting allows for the flattening of the power distribution. The reflector and shield regions of the core correspond to the last three rows of the core. While the ultimate shutdown and primary control rods are shown in the schematic, these were modeled as fully withdrawn.

On the other hand, the radial layout of the metal $C R=0.75$ SFR is slightly different than the $\mathrm{CR}=0.50$ design. The inner core region is decreased by converting the outer row into a middle core region row. The outer core region is increased by converting the second middle core row into an outer core row. Other than this change in enrichment splitting, the rest of the core layout remains identical. A schematic of this layout is shown below in Figure 3.2. 


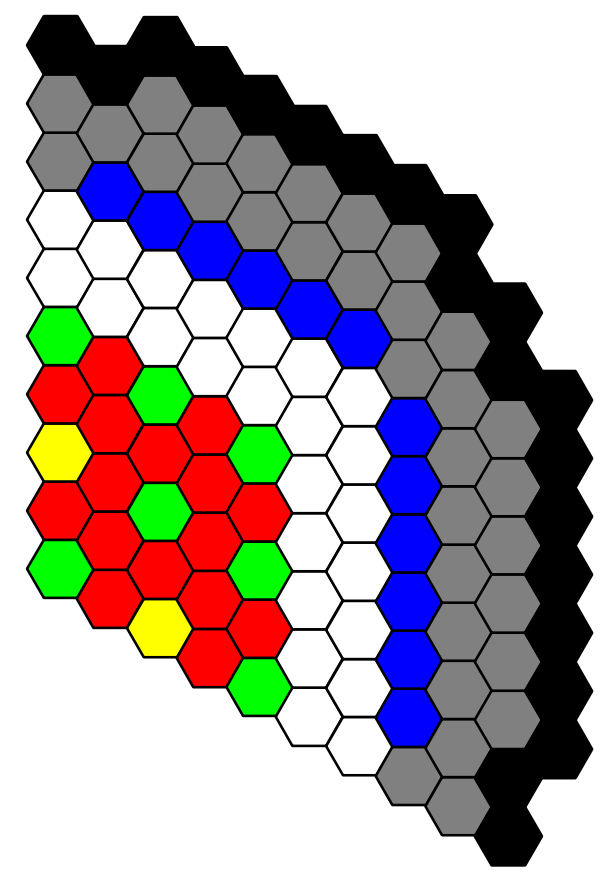

Driver Assemblies (144 total)

$\square$ Inner Core (42)

$\square$ Middle Core (66)

$\checkmark$ Outer Core (36)

$\square$ Ultimate Shutdown (3)

Primary Control Rod (16)

Reflector (90)

Shield (60)

Figure 3-1 One Third Symmetric Radial Layout of Metal Fuel CR=0.50 SFR Design.

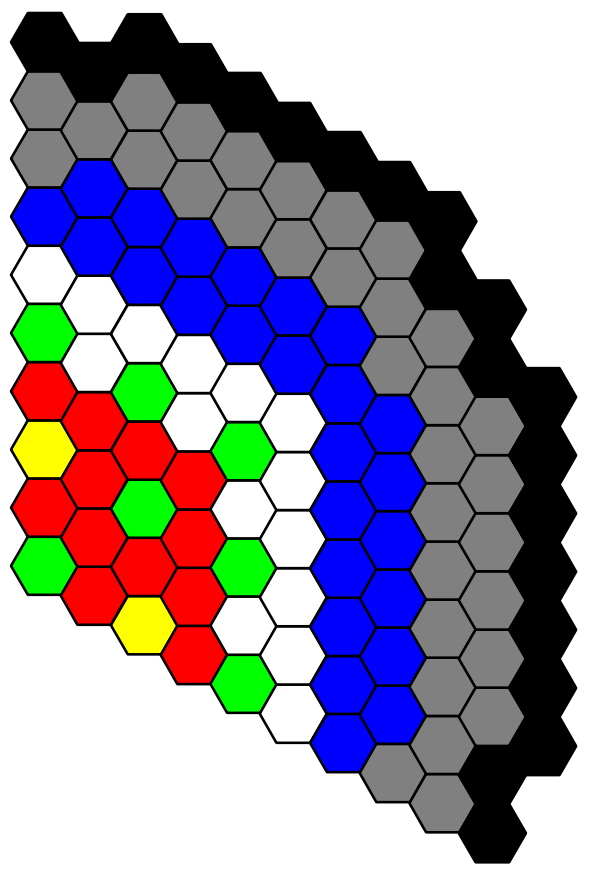

Driver Assemblies (144 total)

Inner Core (30)

$\Longrightarrow$ Middle Core (42)

Outer Core (72)

$\Longrightarrow$ Ultimate Shutdown (3)

Primary Control Rod (16)

Reflector (90)

Shield (60)

Figure 3-2 One Third Symmetric Radial Layout of Metal Fuel CR=0.75 SFR Design. 


\subsubsection{Oxide Fuel Sodium Fast Reactor}

The radial layout of the oxide core, similar to the metal SFR, consists of three driver fuel regions; the inner, middle, and outer core. A schematic of this layout is shown below in Figure 3.3. The inner core consists of five rows containing a total of 72 assemblies while the middle core consists of one row containing a total of 36 assemblies with a charge TRU enrichment of 1.25 times that of the inner core. Finally, the outer core consists of a single row containing 36 assemblies with a charge TRU enrichment of 1.50 times that of the inner core. The reflector, shield, the ultimate shutdown and primary control rods were modeled as fully withdrawn. Unlike in the case of the metal SFR, the core layout remains identical for both $\mathrm{CR}=0.50$ and $\mathrm{CR}=0.75$ designs.
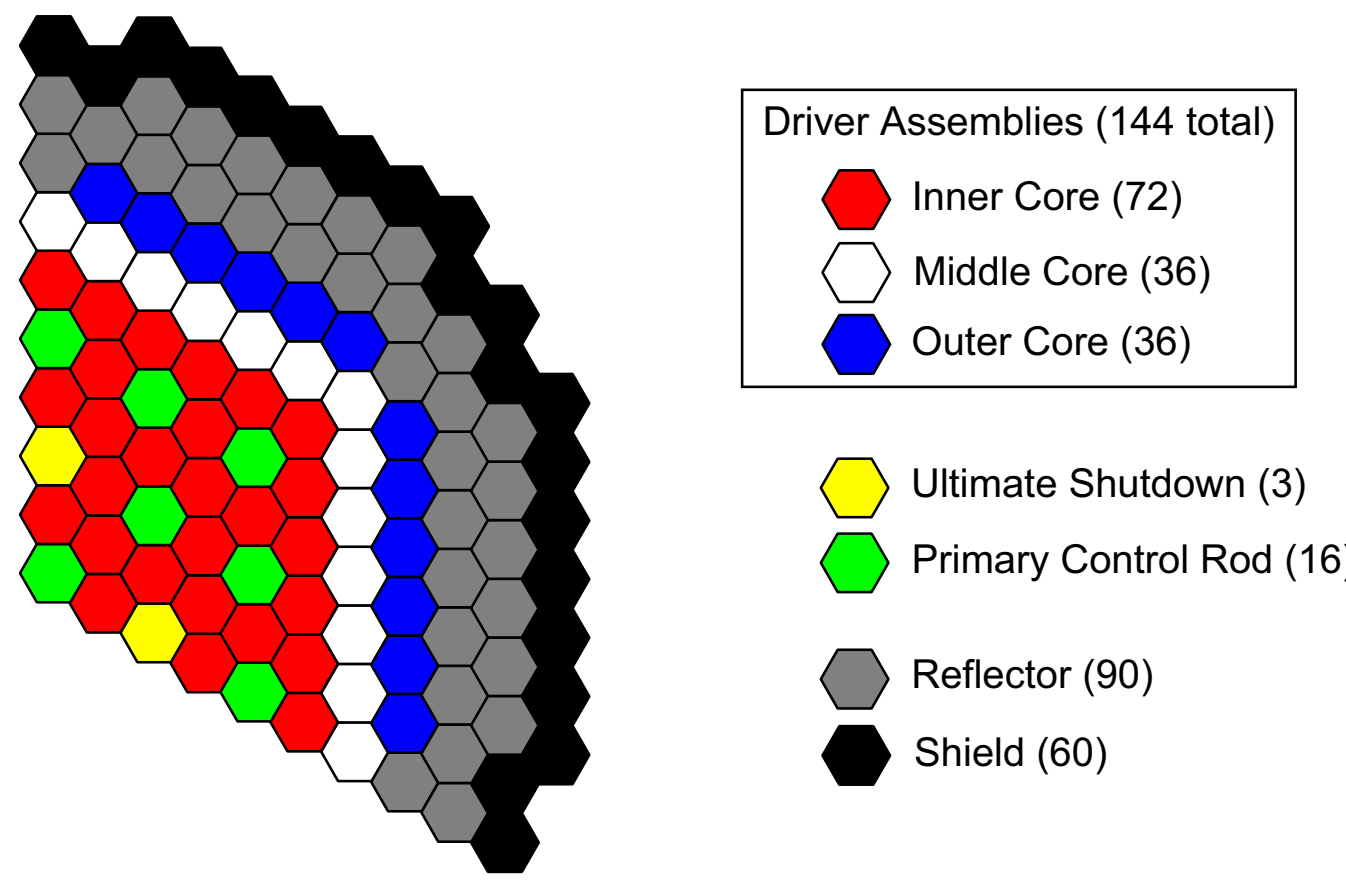

Reflector (90)

Shield (60)

Figure 3-3 One Third Symmetric Radial Layout of Oxide Fuel CR=0.50, 0.75 SFR Design.

\subsection{External Fuel Cycle Models}

In this study, the TRU component of LWR SNF is assumed to be separated through aqueous separation and sent to the fuel fabrication plant to be converted into SFR fuel. The discharged fuel from the SFR is reprocessed through electrochemical reprocessing (in the case of metal fuel) or aqueous separation (in the case of oxide fuel), and fed back into the fuel fabrication plant. Depleted uranium is assumed to be the only other external feed to provide fuel material to the fuel fabrication plant. The fuel fabrication plant feeds the SFR with the necessary charge isotopic vector. The reduced waste from this fuel cycle is assumed to be sent to interim storage or geologic repository. A schematic of this process is presented below in Figure 3.4. 

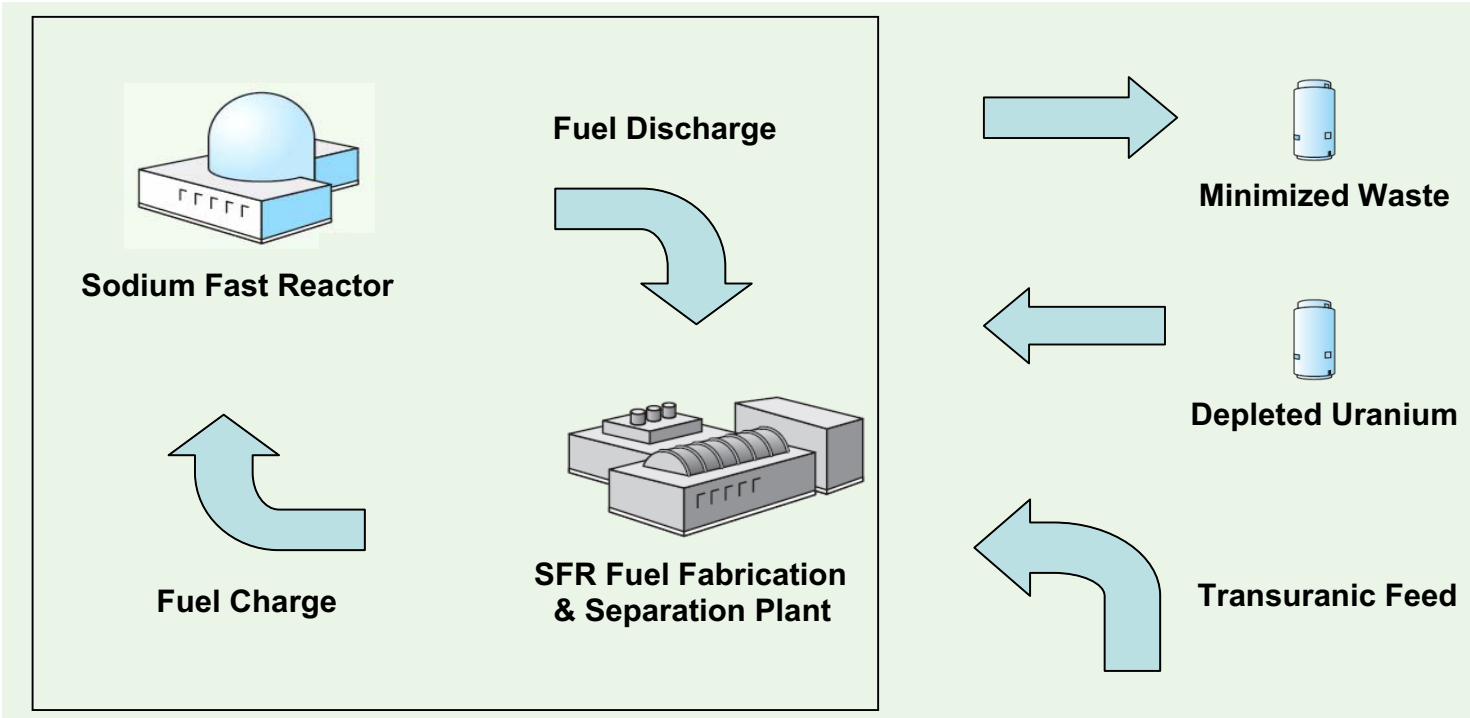

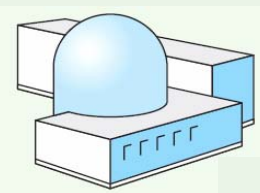

Light Water Reactor

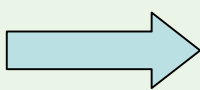

LWR SNF

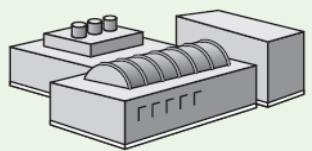

LWR Spent Nuclear Fuel Separation Plant

Figure 3-4 Reference SFR External Fuel Cycle.

The application of different separation processes to the SFR fuel cycle will involve the inclusion and exclusion of certain TRU isotopes from either the LWR SNF, the discharge fast reactor fuel, or both. The relation between the 'groupings' of TRU isotopes and the aqueous separation processes is summarized below in Table 3.2. Note that berkelium and californium are included in UREX $+1 \mathrm{a}$.

Table 3-2 Aqueous Separation Processes and Relationship to Transuranic Groupings.

\begin{tabular}{|c|c|}
\hline Separation Process & TRU Makeup Feed \\
\hline PUREX & $\mathrm{Pu}$ \\
\hline UREX+2/+3 & $\mathrm{Np}+\mathrm{Pu}$ \\
\hline UREX +4 & $\mathrm{~Np}+\mathrm{Pu}+\mathrm{Am}$ \\
\hline UREX $+1 \mathrm{a}$ & All Transuranics \\
\hline
\end{tabular}

\subsubsection{Alternate Metal Fuel SFR External Fuel Cycles}

Three alternate external fuel cycles for the metal fuel $\mathrm{CR}=0.50 \mathrm{SFR}$ design were analyzed. The first involves the separation of plutonium from the LWR SNF (PUREX) and the reprocessing of SFR discharge homogeneously through electrochemical reprocessing. The second alternate external fuel cycle involves the separation of neptunium and plutonium (UREX+2/+3) from LWR SNF and reprocessing SFR discharge through the same electrochemical reprocessing technique. Finally, the third alternate external fuel cycle involves the separation of neptunium, plutonium, and americium (UREX+4) from the LWR spent fuel and reprocessing SFR discharge through the same electrochemical reprocessing technique. In all cases it is assumed that the excluded isotopes are disposed of externally.

Due to the nature of reprocessing fuel discharged through electrochemical reprocessing, all the TRU produced in a cycle burn gets charged again into the SFR as part of the fresh fuel. 


\subsubsection{Alternate Oxide Fuel SFR External Fuel Cycles}

The reprocessing of the oxide fuel discharge through aqueous separation allows the partitioning of isotopes that are to be fabricated into new fuel. In the case of oxide fuel, the minor actinides can be isolated from each other in the fuel discharge and disposed of in different ways. The case of using $\mathrm{UREX}+1$ a for aqueous separation in the reprocessing yields a parallel process to that of electrochemical reprocessing metal fuel, in which all the transuranic are fabricated into fresh fuel and charged back into the SFR.

In the case of alternate oxide fuel external cycles, the LWR SNF is separated through PUREX, $\mathrm{UREX}+2 /+3$, UREX+4, or UREX+1a. While in the case of metal fuel all the TRU is charged back into the reactor, regardless of the initial LWR SNF separation, in the case of oxide it is possible to apply the same separation process as in the external feed. Thus, at equilibrium, the oxide SFR will be generating a net amount of TRU that is assumed to be disposed by some internal separation strategy.

\subsection{Light Water Reactor Spent Nuclear Fuel External Feeds}

The relative concentration of TRU in LWR SNF being stored is dependent on the burnup and the cooling time it has been exposed to. Since the purpose of the SFR is to use this SNF as feed, it is necessary to determine what effects different fuel 'vintages' would have on relevant reactor physics, fuel cycle, and fuel handling parameters. For this purpose, three LWR SNF vectors were generated for three different cases; a low burnup and long cooling time (33 MWd/kg 30 year cooled), a high burnup and medium cooling time (51 MWd/kg 10 year cooled), and a reference or base case with a high burnup and a short cooling time (51 MWd/kg 5 year cooled.) The resulting TRU vectors are shown below in Table 3.3.

Table 3-3 External TRU Isotopic Feed Vectors in Weight Percent for Multiple LWR SNF 'Vintages'.

\begin{tabular}{|c|c|c|c|}
\hline \multirow[b]{2}{*}{ Isotopes } & \multicolumn{3}{|c|}{ Burnup (MWd/kg), Cooling Time (yr) } \\
\hline & $\begin{array}{l}51 \mathrm{MWd} / \mathrm{kg}, 5 \mathrm{yr} \\
\text { (Reference Case) }\end{array}$ & $51 \mathrm{MWd} / \mathrm{kg}, 10 \mathrm{yr}$ & $33 \mathrm{MWd} / \mathrm{kg}, 30 \mathrm{yr}$ \\
\hline $\mathrm{Np}-237$ & $5.3038 \mathrm{E}-02$ & $5.3450 \mathrm{E}-02$ & $4.2508 \mathrm{E}-02$ \\
\hline Pu-238 & $2.6160 \mathrm{E}-02$ & 2.5184E-02 & 1.2376E-02 \\
\hline Pu-239 & $4.8048 \mathrm{E}-01$ & 4.8098E-01 & 5.4395E-01 \\
\hline $\mathrm{Pu}-240$ & 2.1616E-01 & $2.1746 \mathrm{E}-01$ & $2.1930 \mathrm{E}-01$ \\
\hline Pu-241 & $1.0428 \mathrm{E}-01$ & $8.2038 \mathrm{E}-02$ & $2.9062 \mathrm{E}-02$ \\
\hline Pu-242 & $6.1756 \mathrm{E}-02$ & $6.1829 \mathrm{E}-02$ & 4.4895E-02 \\
\hline Am-241 & 3.3425E-02 & $5.5491 \mathrm{E}-02$ & $9.7175 \mathrm{E}-02$ \\
\hline Am-242m & 1.1307E-04 & $1.1048 \mathrm{E}-04$ & 9.9897E-05 \\
\hline Am-243 & 1.7275E-02 & $1.7288 \mathrm{E}-02$ & $9.5270 \mathrm{E}-03$ \\
\hline $\mathrm{Cm}-242$ & 1.1037E-06 & 3.7083E-07 & 2.6202E-07 \\
\hline $\mathrm{Cm}-243$ & 5.3366E-05 & 4.7315E-05 & 1.6023E-05 \\
\hline $\mathrm{Cm}-244$ & $6.6230 \mathrm{E}-03$ & 5.4757E-03 & $9.2911 \mathrm{E}-04$ \\
\hline $\mathrm{Cm}-245$ & $5.7519 \mathrm{E}-04$ & $5.7559 \mathrm{E}-04$ & $1.5162 \mathrm{E}-04$ \\
\hline $\mathrm{Cm}-246$ & $6.7242 \mathrm{E}-05$ & $6.7273 E-05$ & 1.2412E-05 \\
\hline $\mathrm{Cm}-247$ & $1.1858 \mathrm{E}-06$ & 1.1872E-06 & 1.4336E-07 \\
\hline Cm-248 & $9.0107 \mathrm{E}-08$ & $9.0214 \mathrm{E}-08$ & 7.1153E-09 \\
\hline Cf-249 & 1.4706E-09 & 1.4821E-09 & $8.1270 \mathrm{E}-11$ \\
\hline Cf-250 & $4.2611 \mathrm{E}-10$ & $3.2738 \mathrm{E}-10$ & $5.7606 \mathrm{E}-12$ \\
\hline Cf-251 & $2.4317 \mathrm{E}-10$ & $2.4255 \mathrm{E}-10$ & $9.9988 \mathrm{E}-12$ \\
\hline Cf-252 & 4.0293E-11 & $1.0894 \mathrm{E}-11$ & $1.7475 \mathrm{E}-15$ \\
\hline
\end{tabular}

NOTE: $\quad$ Because of its short half-life, Am-242 was split between $\mathrm{Cm}-242(83 \%)$ and Pu-242(17\%) 


\subsection{Startup Cycles}

Four additional alternative studies were performed to analyze the impact of various feeds on the initial recycling cycle. These studies assume that the fuel that is loaded in the reactor comes entirely from the external feed (i.e. no reprocessing). The four feed that were studied are: 1) Pu recycled from LWR $\mathrm{SNF}(51 \mathrm{MWd} / \mathrm{kg} 5$ year cooled), 2) Np-Pu recycled from LWR SNF, 3) weapons-grade Pu (93.5\% Pu239, 6.5\% Pu-240) and 4) enriched uranium. These studies were requested to perform system analysis simulations in which the fast reactor would come online before the full reprocessing capabilities. The fuel is assumed to be metallic and the SFR design corresponds to the previously described $\mathrm{CR}=0.5$ dimensions and properties. 


\section{Analysis Results}

This section summarizes the results of the fuel cycle analysis for the metal and oxide $\mathrm{CR}=0.50$ and 0.75 SFR designs. A matrix of perturbed cases was created by taking the $\mathrm{CR}=0.50 \mathrm{SFR}$ design and varying fuel composition, external feed TRU vector, and separation and reprocessing schemes, but only results that give valuable insight to the problem are presented. For example, very little variation was found in the TRU enrichment, cycle length, and TRU consumption between the different TRU vectors, so only the results from the reference TRU vector $(51 \mathrm{MWd} / \mathrm{kg} 5$ year cooled) were used in the calculation of the neutron emission, gamma energy, and decay heat of the equilibrium charge.

\subsection{Reactor Physics, Fuel Cycle and Displacements-Per-Atom Calculations}

The results from the fuel cycle calculations are tabulated in Tables 4.1 and 4.2 for metal and oxide $\mathrm{CR}=0.50 \mathrm{SFR}$ designs, respectively. Some of the parameters listed include the TRU enrichment for each zone, the fuel residence time in cycles, cycle length, fluence, DPA, and TRU consumption rate per Effective Full Power Year (EFPY.) The general approach taken in this study with regards to the conversion ratio was to differentiate between the 'design' conversion ratio and the 'actual' conversion ratio. The conversion ratio 'design' refers to the SFR designs described in Reference 6. Of course, varying the external feed and groupings will change the 'actual' conversion ratio, which is allowed to 'float'. Thus, an 'actual' conversion ratio is reported for each common design in Tables 4.1 and 4.2.

No major variations in the fuel cycle parameters were found when the separation process was varied while holding constant the external feed. As expected, the more plutonium-rich external feeds (PUREX having the largest weight percent of fissile plutonium), the smaller the TRU enrichment necessary to meet the cycle length. As other minor actinide (MA) isotopes are included in the feed, such as americium and curium, the fissile worth of the TRU vector is degraded. Thus, higher TRU enrichment is necessary in order to meet similar cycle lengths. This is observed in both the metal and oxide SFR cases, although in the case of the latter, the TRU enrichment for the PUREX is much lower than UREX $+1 \mathrm{a}$, since the reprocessed charge is free of TRU other than the plutonium.

Perturbing the external feed by selecting different LWR SNF vintages had less of an impact on fuel cycle parameters than varying the separation strategy described above. For example, in the case of UREX +1 a, the TRU enrichment varies only a few fractions of a percent for all three TRU vectors. All other fuel cycle parameters have similar variations relative to one another. A closer look at the relative concentration of fissile plutonium present in the 'older' fuel vintage (33 MWd/kg 30 year cooled) versus the 'younger' vintage $(51 \mathrm{MWd} / \mathrm{kg} 5$ year cooled) reveals that the total weight percent of fissile plutonium is very similar between the two. This gives all three TRU vectors a similar fissile worth from the point of view of having the necessary reactivity needed by the SFR to meet its cycle length objective. 
Table 4-1 Fuel Cycle Results for Metal CR=0.50 SFR Design for Multiple Separation Processes and LWR SNF 'Vintages".

\begin{tabular}{|c|c|c|c|c|c|c|c|c|c|c|c|c|c|}
\hline & & \multicolumn{4}{|c|}{$51 \mathrm{MWd} / \mathrm{kg}, 5 \mathrm{yr}$} & \multicolumn{4}{|c|}{$51 \mathrm{MWd} / \mathrm{kg}, 10 \mathrm{yr}$} & \multicolumn{4}{|c|}{$33 \mathrm{MWd} / \mathrm{kg}, 30 \mathrm{yr}$} \\
\hline \multicolumn{2}{|c|}{ Separation Groupings } & PUREX & UREX+2/+3 & UREX+4 & UREX+1a & PUREX & UREX+2/+3 & UREX+4 & UREX+1a & PUREX & UREX+2/+3 & UREX+4 & UREX+1a \\
\hline \multicolumn{2}{|c|}{ Actual Conversion Ratio } & 0.54 & 0.53 & 0.53 & 0.53 & 0.54 & 0.54 & 0.52 & 0.52 & 0.55 & 0.54 & 0.52 & 0.52 \\
\hline \multirow{3}{*}{$\begin{array}{c}\text { Charge } \\
\text { Enrichment, } \\
\text { TRU/HM (v/f) }\end{array}$} & IC & $25.7 \%$ & $26.0 \%$ & $26.6 \%$ & $26.6 \%$ & $25.8 \%$ & $26.1 \%$ & $26.9 \%$ & $26.9 \%$ & $25.2 \%$ & $25.5 \%$ & $26.6 \%$ & $26.6 \%$ \\
\hline & MC & $32.1 \%$ & $32.5 \%$ & $33.2 \%$ & $33.2 \%$ & $32.2 \%$ & $32.6 \%$ & $33.6 \%$ & $33.6 \%$ & $31.6 \%$ & $31.8 \%$ & $33.2 \%$ & $33.3 \%$ \\
\hline & OC & $38.6 \%$ & $39.0 \%$ & $39.8 \%$ & $39.8 \%$ & $38.7 \%$ & $39.1 \%$ & $40.3 \%$ & $40.3 \%$ & $37.9 \%$ & $38.2 \%$ & $39.9 \%$ & $39.9 \%$ \\
\hline \multirow{3}{*}{$\begin{array}{l}\text { Fuel residence } \\
\text { time, cycles }\end{array}$} & IC & 6 & 6 & 6 & 6 & 6 & 6 & 6 & 6 & 6 & 6 & 6 & 6 \\
\hline & MC & 6 & 6 & 6 & 6 & 6 & 6 & 6 & 6 & 6 & 6 & 6 & 6 \\
\hline & OC & 7 & 7 & 7 & 7 & 7 & 7 & 7 & 7 & 7 & 7 & 7 & 7 \\
\hline Burnup (MWd/kg) & $\begin{array}{l}\text { Ave. } \\
\text { Driver }\end{array}$ & 131.3 & 131.3 & 130.8 & 131.2 & 131.3 & 131.3 & 131.0 & 131.1 & 131.4 & 130.7 & 130.3 & 130.9 \\
\hline \multirow{3}{*}{$\begin{array}{c}\text { Peak Fast } \\
\text { Fluence, } 10^{\star *} 23 \\
\text { n/cm } 23\end{array}$} & IC & 4.00 & 4.00 & 3.99 & 4.00 & 4.00 & 4.00 & 4.00 & 4.00 & 4.00 & 4.00 & 3.99 & 4.00 \\
\hline & MC & 3.99 & 3.98 & 3.96 & 3.97 & 3.99 & 3.97 & 3.96 & 3.96 & 3.98 & 3.97 & 3.93 & 3.95 \\
\hline & OC & 3.80 & 3.77 & 3.74 & 3.74 & 3.79 & 3.76 & 3.73 & 3.73 & 3.78 & 3.75 & 3.69 & 3.70 \\
\hline \multirow{3}{*}{ Maximum DPA } & IC & 181 & 182 & 182 & 183 & 182 & 183 & 183 & 183 & 183 & 183 & 183 & 183 \\
\hline & MC & 191 & 191 & 190 & 191 & 192 & 192 & 191 & 191 & 192 & 191 & 189 & 190 \\
\hline & $\mathrm{OC}$ & 177 & 176 & 174 & 175 & 177 & 176 & 174 & 174 & 177 & 175 & 172 & 173 \\
\hline \multicolumn{2}{|c|}{ HM loading, kg } & 9,462 & 9,467 & 9,419 & 9,410 & 9,462 & 9,468 & 9,396 & 9,390 & 9,463 & 9,470 & 9,367 & 9,363 \\
\hline \multicolumn{2}{|c|}{ TRU loading, kg } & 2,920 & 2,958 & 3,002 & 3,000 & 2,930 & 2,964 & 3,031 & 3,028 & 2,868 & 2,895 & 2,989 & 2,990 \\
\hline \multicolumn{2}{|c|}{ Fissile Pu loading, $\mathrm{kg}$} & 1,372 & 1,358 & 1,333 & 1,328 & 1,371 & 1,356 & 1,323 & 1,318 & 1,401 & 1,388 & 1,340 & 1,340 \\
\hline \multicolumn{2}{|c|}{ Cycle length, EFPD } & 220 & 220 & 218 & 218 & 220 & 219 & 218 & 218 & 219 & 219 & 216 & 217 \\
\hline \multicolumn{2}{|c|}{$\begin{array}{c}\text { TRU Consumption Rate, } \\
\text { kg/EFPY }\end{array}$} & 159.4 & 162.5 & 165.4 & 165.7 & 159.8 & 162.8 & 168.7 & 167.1 & 157.5 & 159.0 & 166.4 & 166.7 \\
\hline \multicolumn{2}{|c|}{ TRU Charge, kg/EFPY } & 848 & 860 & 879 & 879 & 852 & 864 & 895 & 887 & 836 & 845 & 883 & 880 \\
\hline \multicolumn{2}{|c|}{ HM Charge, kg/EFPY } & 2,696 & 2,700 & 2,706 & 2,704 & 2,700 & 2,709 & 2,725 & 2,701 & 2,707 & 2,713 & 2,715 & 2,704 \\
\hline
\end{tabular}


Table 4-2 Fuel Cycle Results for Oxide CR=0.50 SFR Design for Multiple Separation Processes and LWR SNF 'Vintages'.

\begin{tabular}{|c|c|c|c|c|c|c|c|c|c|c|c|c|c|}
\hline & & \multicolumn{4}{|c|}{$51 \mathrm{MWd} / \mathrm{kg}, 5 \mathrm{yr}$} & \multicolumn{4}{|c|}{$51 \mathrm{MWd} / \mathrm{kg}, 10 \mathrm{yr}$} & \multicolumn{4}{|c|}{$33 \mathrm{MWd} / \mathrm{kg}, 30 \mathrm{yr}$} \\
\hline \multicolumn{2}{|c|}{ Separation Groupings } & PUREX & UREX+2/+3 & UREX+4 & UREX+1a & PUREX & UREX $+2 /+3$ & UREX+4 & UREX+1a & PUREX & UREX+2/+3 & UREX+4 & UREX+1a \\
\hline \multicolumn{2}{|c|}{ Actual Conversion Ratio } & 0.53 & 0.52 & 0.49 & 0.51 & 0.53 & 0.52 & 0.49 & 0.50 & 0.54 & 0.53 & 0.49 & 0.51 \\
\hline \multirow{3}{*}{$\begin{array}{c}\text { Charge } \\
\text { Enrichment, } \\
\text { TRU/HM (v/f) }\end{array}$} & IC & $30.9 \%$ & $31.4 \%$ & $33.3 \%$ & $32.6 \%$ & $31.1 \%$ & $31.5 \%$ & $33.6 \%$ & $32.9 \%$ & $30.5 \%$ & $30.8 \%$ & $33.0 \%$ & $32.5 \%$ \\
\hline & $\mathrm{MC}$ & $38.6 \%$ & $39.2 \%$ & $41.6 \%$ & $40.8 \%$ & $38.9 \%$ & $39.4 \%$ & $42.0 \%$ & $41.1 \%$ & $38.1 \%$ & $38.6 \%$ & $41.3 \%$ & $40.6 \%$ \\
\hline & OC & $46.3 \%$ & $47.1 \%$ & $49.9 \%$ & $48.9 \%$ & $46.6 \%$ & $47.3 \%$ & $50.4 \%$ & $49.4 \%$ & $45.7 \%$ & $46.3 \%$ & $49.5 \%$ & $48.7 \%$ \\
\hline \multirow{3}{*}{$\begin{array}{l}\text { Fuel residence } \\
\text { time, cycles }\end{array}$} & IC & 6 & 6 & 6 & 6 & 6 & 6 & 6 & 6 & 6 & 6 & 6 & 6 \\
\hline & MC & 6 & 6 & 6 & 6 & 6 & 6 & 6 & 6 & 6 & 6 & 6 & 6 \\
\hline & OC & 7 & 7 & 7 & 7 & 7 & 7 & 7 & 7 & 7 & 7 & 7 & 7 \\
\hline Burnup (MWd/kg) & $\begin{array}{l}\text { Ave. } \\
\text { Driver }\end{array}$ & 168.7 & 169.3 & 168.6 & 167.5 & 168.7 & 169.3 & 169.1 & 167.9 & 168.7 & 169.3 & 169.4 & 168.3 \\
\hline \multirow{3}{*}{$\begin{array}{c}\text { Peak Fast } \\
\text { Fluence, } 10^{* *} 23 \\
\text { n/cm**2 }\end{array}$} & IC & 3.89 & 3.91 & 3.89 & 3.92 & 3.89 & 3.92 & 3.91 & 3.94 & 3.90 & 3.93 & 3.95 & 3.98 \\
\hline & $\mathrm{MC}$ & 3.85 & 3.86 & 3.85 & 3.87 & 3.85 & 3.86 & 3.87 & 3.88 & 3.86 & 3.87 & 3.88 & 3.89 \\
\hline & OC & 3.99 & 3.98 & 3.98 & 3.98 & 3.98 & 3.98 & 3.99 & 3.99 & 3.99 & 3.98 & 3.99 & 3.99 \\
\hline \multirow{3}{*}{ Maximum DPA } & IC & 190 & 192 & 191 & 192 & 190 & 193 & 192 & 194 & 192 & 194 & 195 & 196 \\
\hline & MC & 198 & 199 & 199 & 200 & 198 & 199 & 200 & 201 & 199 & 200 & 201 & 201 \\
\hline & $\mathrm{OC}$ & 199 & 199 & 200 & 200 & 199 & 199 & 200 & 200 & 199 & 199 & 200 & 200 \\
\hline \multicolumn{2}{|c|}{ HM loading, kg } & 10,843 & 10,836 & 10,849 & 10,856 & 10,844 & 10,837 & 10,851 & 10,857 & 10,846 & 10,840 & 10,855 & 10,860 \\
\hline \multicolumn{2}{|c|}{ TRU loading, kg } & 3,882 & 3,945 & 4,186 & 4,115 & 3,912 & 3,961 & 4,233 & 4,153 & 3,833 & 3,878 & 4,159 & 4,096 \\
\hline \multicolumn{2}{|c|}{ Fissile Pu loading, kg } & 1,856 & 1,832 & 1,774 & 1,709 & 1,858 & 1,829 & 1,762 & 1,698 & 1,887 & 1,864 & 1,783 & 1,731 \\
\hline \multicolumn{2}{|c|}{ Cycle length, EFPD } & 329 & 330 & 329 & 327 & 329 & 330 & 330 & 328 & 329 & 330 & 331 & 329 \\
\hline \multicolumn{2}{|c|}{$\begin{array}{c}\text { TRU Consumption Rate, } \\
\text { kg/EFPY }\end{array}$} & 166.3 & 170.6 & 181.0 & 175.8 & 167.4 & 170.8 & 182.8 & 177.2 & 164.0 & 167.1 & 180.0 & 175.4 \\
\hline \multicolumn{2}{|c|}{ TRU Charge, kg/EFPY } & 763 & 774 & 823 & 812 & 769 & 777 & 829 & 817 & 753 & 760 & 812 & 804 \\
\hline \multicolumn{2}{|c|}{ HM Charge, kg/EFPY } & 2,103 & 2,095 & 2,103 & 2,116 & 2,103 & 2,095 & 2,097 & 2,110 & 2,102 & 2,095 & 2,091 & 2,104 \\
\hline
\end{tabular}


As of today, there are no specific SFR 'point designs' that can be selected as the choice fast reactor to be built in the immediate future. Changing needs and further research will probably dictate which design is the most suitable for initial deployment. While this study focuses mainly on metal and oxide $\mathrm{CR}=0.50 \mathrm{SFR}$ designs, it is necessary to point out that this is by no means a specific choice made by this research group. In fact, a whole suite of SFR design has been developed with conversion ratios ranging from $\mathrm{CR}=1.0$ or breakeven to theoretical $\mathrm{CR}=0.0$ designs. Currently there is a rising interest in intermediate designs $(\mathrm{CR}=0.50,0.75)$ and thus the choice of analyzing these systems. Due to the similarities between these two designs, general trends from a perturbed design would most probably apply to the other. Thus Table 4.3 summarizes the fuel cycle analysis results for metal and oxide $\mathrm{CR}=0.75 \mathrm{SFR}$ designs which may be utilized to perform further investigations (such as the introduction of transuranics targets for maximized TRU destruction.)

Table 4-3 Fuel Cycle Results for Metal and Oxide CR=0.75 SFR Design for Reference UREX+1a and LWR SNF vector.

\begin{tabular}{|c|c|c|c|}
\hline & & Metal Fuel SFR & Oxide Fuel SFR \\
\hline & & $51 \mathrm{MWd} / \mathrm{kg}, 5 \mathrm{yr}$ & $51 \mathrm{MWd} / \mathrm{kg}, 5 \mathrm{yr}$ \\
\hline \multicolumn{2}{|c|}{ Separation Groupings } & UREX+1a & UREX+1a \\
\hline \multicolumn{2}{|c|}{ Actual Conversion Ratio } & 0.77 & 0.75 \\
\hline \multirow{3}{*}{$\begin{array}{c}\text { Charge } \\
\text { Enrichment, } \\
\text { TRU/HM (v/f) }\end{array}$} & IC & $15.7 \%$ & $21.8 \%$ \\
\hline & MC & $19.6 \%$ & $27.2 \%$ \\
\hline & $\mathrm{OC}$ & $23.5 \%$ & $32.7 \%$ \\
\hline \multirow{3}{*}{$\begin{array}{l}\text { Fuel residence } \\
\text { time, cycles }\end{array}$} & IC & 6 & 6 \\
\hline & MC & 6 & 6 \\
\hline & OC & 6 & 7 \\
\hline $\begin{array}{l}\text { Burnup } \\
\text { (MWd/kg) }\end{array}$ & $\begin{array}{l}\text { Ave. } \\
\text { Driver }\end{array}$ & 99.2 & 133.1 \\
\hline \multirow{3}{*}{$\begin{array}{c}\text { Peak Fast } \\
\text { Fluence, } 10^{\star \star} 23 \\
\text { n/cm**2 }\end{array}$} & IC & 3.85 & 4.00 \\
\hline & $\mathrm{MC}$ & 4.00 & 3.88 \\
\hline & OC & 3.98 & 3.92 \\
\hline \multicolumn{2}{|c|}{ HM loading, kg } & 13,350 & 15,166 \\
\hline \multicolumn{2}{|c|}{ TRU loading, kg } & 2,775 & 3,954 \\
\hline \multicolumn{2}{|c|}{ Fissile Pu loading, kg } & 1,515 & 1,964 \\
\hline \multicolumn{2}{|c|}{ Cycle length, EFPD } & 229 & 356 \\
\hline \multicolumn{2}{|c|}{$\begin{array}{c}\text { TRU Consumption Rate, } \\
\text { kg/EFPY }\end{array}$} & 73.8 & 83.6 \\
\hline \multicolumn{2}{|c|}{ TRU Charge, kg/EFPY } & 738 & 682 \\
\hline \multicolumn{2}{|c|}{ HM Charge, kg/EFPY } & 3,577 & 2,660 \\
\hline
\end{tabular}

The rates of consumption, reported in kg per Effective Full Power Year (EFPY), for TRU are tabulated in Table 4.4. As shown in the table, the total TRU consumption rates increase as more transuranics are loaded into the driver fuel. Thus, the highest consumption rate occurs for UREX $+1 \mathrm{a}$ and the lowest for PUREX. The reason why more TRU is loaded into the fuel in the case of UREX+1a is due to the higher TRU enrichment needed to meet the cycle length. As Table 4.1 shows for the metal fuel, the UREX +1 a case requires $26.6 \%$ TRU enrichment versus $25.7 \%$ in the PUREX case. This difference is due to the fact that the fissile worth of the external feed is being degraded in the case of UREX $+1 \mathrm{a}$ as compared to the PUREX feed. 
Another important trend to note is the net production of certain TRU isotopes in the fast spectrum. These net productions of TRU come from the parasitic capture of neutrons by certain isotopes, which still occur in the fast spectrum. The main TRU isotopes being produced in the fast spectrum due to parasitic capture are Cm-242 and Cm-244. Their presence is explained by the transmutation physics occurring throughout the cycle. The capture of a neutron by Am-241 leads $90 \%$ of the time to Am-242, which has a 16 hour half-life and subsequently decays into Cm-242 through beta decay. This also accounts for all the consumption of Am-241, even when not introduced from makeup feed. Its presence is due to beta decay of $\mathrm{Pu}-241$, which has a 14.4 year half-life. The other important transmutation physics pathway to note is the production of $\mathrm{Cm}-244$. The production of this $\mathrm{Cm}-244$ comes from Am-243 capturing a neutron, becoming Am-244 (which has a 10.1 hour half-life), and decaying into $\mathrm{Cm}-244$. Thus the presence of Am-241 and Am-243 built up from decay and capture eventually lead to their transmutation into Cm-242 and $\mathrm{Cm}-244$, respectively.

Table 4-4 Consumption Rates (kg/EFPY) for Metal CR=0.50 SFR Design for Multiple Separation Processes.

\begin{tabular}{|c|c|c|c|c|}
\hline \multirow[b]{2}{*}{ Separation Groupings } & \multicolumn{4}{|c|}{ Metal Fuel } \\
\hline & PUREX & UREX $+2 /+3$ & UREX+4 & UREX+1a \\
\hline $\mathrm{Np}-237$ & 0.03 & 9.20 & 8.89 & 8.83 \\
\hline $\mathrm{Np}-238$ & 0.00 & 0.00 & 0.00 & 0.00 \\
\hline Pu-236 & 0.00 & 0.00 & 0.00 & 0.00 \\
\hline Pu-238 & 5.36 & 5.08 & 5.21 & 5.17 \\
\hline Pu-239 & 86.29 & 83.06 & 80.21 & 79.63 \\
\hline Pu-240 & 39.41 & 37.94 & 36.82 & 36.61 \\
\hline $\mathrm{Pu}-241$ & 16.35 & 15.71 & 15.12 & 15.00 \\
\hline Pu-242 & 11.09 & 10.68 & 10.31 & 10.24 \\
\hline Am-241 & 2.34 & 2.29 & 7.83 & 7.78 \\
\hline$A m-242 m$ & -0.01 & -0.01 & 0.01 & 0.01 \\
\hline Am-243 & 0.00 & 0.00 & 2.88 & 2.86 \\
\hline $\mathrm{Cm}-242$ & -0.80 & -0.78 & -1.10 & -1.09 \\
\hline $\mathrm{Cm}-243$ & 0.00 & 0.00 & 0.00 & 0.01 \\
\hline $\mathrm{Cm}-244$ & -0.63 & -0.61 & -0.77 & 0.27 \\
\hline $\mathrm{Cm}-245$ & 0.00 & 0.00 & 0.00 & 0.09 \\
\hline $\mathrm{Cm}-246$ & 0.00 & 0.00 & 0.00 & 0.01 \\
\hline $\mathrm{Cm}-247$ & 0.00 & 0.00 & 0.00 & 0.00 \\
\hline $\mathrm{Cm}-248$ & 0.00 & 0.00 & 0.00 & 0.00 \\
\hline Bk-249 & 0.00 & 0.00 & 0.00 & 0.00 \\
\hline Cf-249 & 0.00 & 0.00 & 0.00 & 0.00 \\
\hline Cf-250 & 0.00 & 0.00 & 0.00 & 0.00 \\
\hline Cf-251 & 0.00 & 0.00 & 0.00 & 0.00 \\
\hline Cf-252 & 0.00 & 0.00 & 0.00 & 0.00 \\
\hline Total & 159.43 & 162.56 & 165.40 & 165.43 \\
\hline
\end{tabular}

In the case of the oxide SFR, the consumption rates must be interpreted differently than in the case of the metal SFR. The first difference is the production of americium and curium for the cases in which PUREX, UREX+2/+3, or UREX+4 are used for both separation of LWR SNF and reprocessing of oxide fuel discharge from the SFR. As noted in Section III., elemental separation of TRU in oxide reprocessing 
is possible, thus a net stream of those isolated elements is created and reflects as a negative number in Table 4.5.

Similarly for metal fuel case, a higher TRU enrichment causes the TRU consumption to increase. This difference in consumption rate is more dramatic in the oxide fuel case since continual separation of TRU elements is applied during reprocessing. Thus, in the case of PUREX, for example, the reprocessed feed is being 'cleaned' of any other TRU, thus its fissile worth is higher than in the case of UREX+1a.

In the case of UREX +1 a, the same pattern in consumption/production can be seen as in the metallic electrochemical reprocessing. Mainly that Am-241 and Am-243 are transmuted into Cm-242 and Cm244, respectively, from the capture of a neutron.

Table 4-5 Consumption Rates (kg/EFPY) for Oxide CR=0.50 SFR Design for Multiple Separation Processes.

\begin{tabular}{|c|c|c|c|c|}
\hline \multirow[b]{2}{*}{ Separation Groupings } & \multicolumn{4}{|c|}{ Oxide Fuel } \\
\hline & PUREX & UREX+2/+3 & UREX+4 & UREX+1a \\
\hline $\mathrm{Np}-237$ & -0.76 & 11.14 & 10.41 & 9.42 \\
\hline $\mathrm{Np}-238$ & 0.00 & 0.00 & 0.00 & 0.00 \\
\hline $\mathrm{Pu}-236$ & 0.00 & 0.00 & 0.00 & 0.00 \\
\hline $\mathrm{Pu}-238$ & 6.06 & 5.64 & 5.79 & 5.28 \\
\hline Pu-239 & 105.16 & 100.57 & 93.64 & 84.70 \\
\hline Pu-240 & 47.50 & 45.42 & 42.86 & 39.37 \\
\hline Pu-241 & 18.92 & 18.04 & 16.69 & 14.85 \\
\hline Pu-242 & 13.52 & 12.93 & 12.04 & 10.89 \\
\hline $\mathrm{Am}-241$ & -8.63 & -8.41 & 10.08 & 9.36 \\
\hline Am-242m & -0.44 & -0.43 & 0.01 & 0.01 \\
\hline $\mathrm{Am}-243$ & -10.85 & -10.36 & 3.36 & 3.04 \\
\hline $\mathrm{Cm}-242$ & -0.48 & -0.46 & -1.19 & -1.08 \\
\hline $\mathrm{Cm}-243$ & -0.03 & -0.03 & -0.10 & 0.00 \\
\hline $\mathrm{Cm}-244$ & -3.25 & -3.07 & -10.79 & -0.16 \\
\hline $\mathrm{Cm}-245$ & -0.39 & -0.37 & -1.63 & 0.10 \\
\hline $\mathrm{Cm}-246$ & -0.02 & -0.02 & -0.10 & 0.01 \\
\hline $\mathrm{Cm}-247$ & 0.00 & 0.00 & 0.00 & 0.00 \\
\hline $\mathrm{Cm}-248$ & 0.00 & 0.00 & 0.00 & 0.00 \\
\hline Bk-249 & 0.00 & 0.00 & 0.00 & 0.00 \\
\hline Cf-249 & 0.00 & 0.00 & 0.00 & 0.00 \\
\hline Cf-250 & 0.00 & 0.00 & 0.00 & 0.00 \\
\hline Cf-251 & 0.00 & 0.00 & 0.00 & 0.00 \\
\hline Cf-252 & 0.00 & 0.00 & 0.00 & 0.00 \\
\hline Total & 166.31 & 170.60 & 181.05 & 175.80 \\
\hline
\end{tabular}

The issue of fuel vintage arises in these net consumption rate comparisons. A longstanding question is whether an 'older' vintage of LWR SNF can be more effectively transmuted than a 'younger' vintage. As noted in the beginning of this section, the fissile worth of both TRU vectors is very similar, thus no major differences are found in terms of TRU enrichment, cycle length, TRU net consumption, etc. On the other hand, while both TRU vectors have very similar fissile worth, the older vintage contains a higher concentration of Am-241 than the younger vintage. The older vintage also contains a lower 
concentration of curium and the higher mass actinides than the younger vintage. Thus, the parasitic capture of a neutron by Am-241 causes, indirectly, a slight increase in the amount of Cm-242 being produced in the process of transmuting americium in an SFR. For the 'younger vintage' the amount of curium destruction is greater than curium production. This is because the amount of curium present at the start of irradiation in the 'younger' LWR SNF vector is higher than the 'older' LWR SNF. Thus the 'younger' has more curium to burn. Tabulated data for the different consumption rates of 'young' and 'old' LWR SNF vintages is show in Table 4.6.

Table 4-6 Comparison of Consumption Rates (kg/EFPY) Between Metal and Oxide CR=0.50 SFR Design for 'Young' and 'Old' LWR SNF Vintages.

\begin{tabular}{|c|c|c|c|c|}
\hline \multirow[b]{2}{*}{ LWR SNF Vector } & \multicolumn{2}{|c|}{ Metal Fuel } & \multicolumn{2}{|c|}{ Oxide Fuel } \\
\hline & $51 \mathrm{MWd} / \mathrm{kg}, 5 \mathrm{yr}$ & $33 \mathrm{MWd} / \mathrm{kg}, 30 \mathrm{yr}$ & $51 \mathrm{MWd} / \mathrm{kg}, 5 \mathrm{yr}$ & $33 \mathrm{MWd} / \mathrm{kg}, 30 \mathrm{yr}$ \\
\hline $\mathrm{Np}-237$ & 8.83 & 7.15 & 9.42 & 7.56 \\
\hline Np-238 & 0.00 & 0.00 & 0.00 & 0.00 \\
\hline Pu-236 & 0.00 & 0.00 & 0.00 & 0.00 \\
\hline Pu-238 & 5.17 & 3.37 & 5.28 & 3.13 \\
\hline Pu-239 & 79.63 & 90.81 & 84.70 & 95.68 \\
\hline Pu-240 & 36.61 & 37.19 & 39.37 & 39.54 \\
\hline Pu-241 & 15.00 & 2.82 & 14.85 & 1.89 \\
\hline Pu-242 & 10.24 & 7.50 & 10.89 & 7.90 \\
\hline $\mathrm{Am}-241$ & 7.78 & 18.21 & 9.36 & 20.24 \\
\hline$A m-242 m$ & 0.01 & 0.00 & 0.01 & 0.00 \\
\hline $\mathrm{Am}-243$ & 2.86 & 1.59 & 3.04 & 1.67 \\
\hline $\mathrm{Cm}-242$ & -1.09 & -1.60 & -1.08 & -1.38 \\
\hline $\mathrm{Cm}-243$ & 0.01 & 0.00 & 0.00 & -0.01 \\
\hline $\mathrm{Cm}-244$ & 0.27 & -0.46 & -0.16 & -0.86 \\
\hline $\mathrm{Cm}-245$ & 0.09 & 0.02 & 0.10 & 0.03 \\
\hline $\mathrm{Cm}-246$ & 0.01 & 0.00 & 0.01 & 0.00 \\
\hline $\mathrm{Cm}-247$ & 0.00 & 0.00 & 0.00 & 0.00 \\
\hline $\mathrm{Cm}-248$ & 0.00 & 0.00 & 0.00 & 0.00 \\
\hline Bk-249 & 0.00 & 0.00 & 0.00 & 0.00 \\
\hline Cf-249 & 0.00 & 0.00 & 0.00 & 0.00 \\
\hline Cf-250 & 0.00 & 0.00 & 0.00 & 0.00 \\
\hline Cf-251 & 0.00 & 0.00 & 0.00 & 0.00 \\
\hline Cf-252 & 0.00 & 0.00 & 0.00 & 0.00 \\
\hline Total & 165.43 & 166.60 & 175.80 & 175.38 \\
\hline
\end{tabular}




\subsection{Reactor Charge and Discharge Results}

The equilibrium charge mass data for all the alternate external fuel cycle scenarios was processed through ORIGEN-S in order to calculate the neutron emission, gamma energy, and decay heat. The external feed was fixed to the same LWR SNF, namely, $51 \mathrm{MWd} / \mathrm{kg} 5$ year cooled TRU vector. In the case of the decay heat, the data is presented both on a per $\mathrm{kg}$ of TRU and per subassembly basis. This allows a fair comparison between metal and oxide charge decay heat. Furthermore, these results are tabulated along with previous calculations of thermal LWR IMF and MOX charge neutron emission, gamma energy, and decay heat.

\subsubsection{Nuetron Emmission Results}

The neutron emission rate is shown below for all four 'groupings' in Figure 4.1. In the case of the metal fuel SFR the neutron emission remains more or less constant across the different separations. This is due to reprocessing all the TRU together through electrochemical reprocessing. In the case of oxide, however, different aqueous separation processes only allow specific isotopes to be fabricated into new fuel. Thus the neutron emission is more or less the same unless curium and the rest of the higher mass actinides are included. This exact same pattern is found in the case of thermal MOX and IMF, where the neutron emission considerably increases when curium and the higher mass actinides are included.

While only small amounts of higher mass actinides are produced and destroyed in the SFR fuel cycle, small quantities can have significant effects on parameters such as the neutron emission.

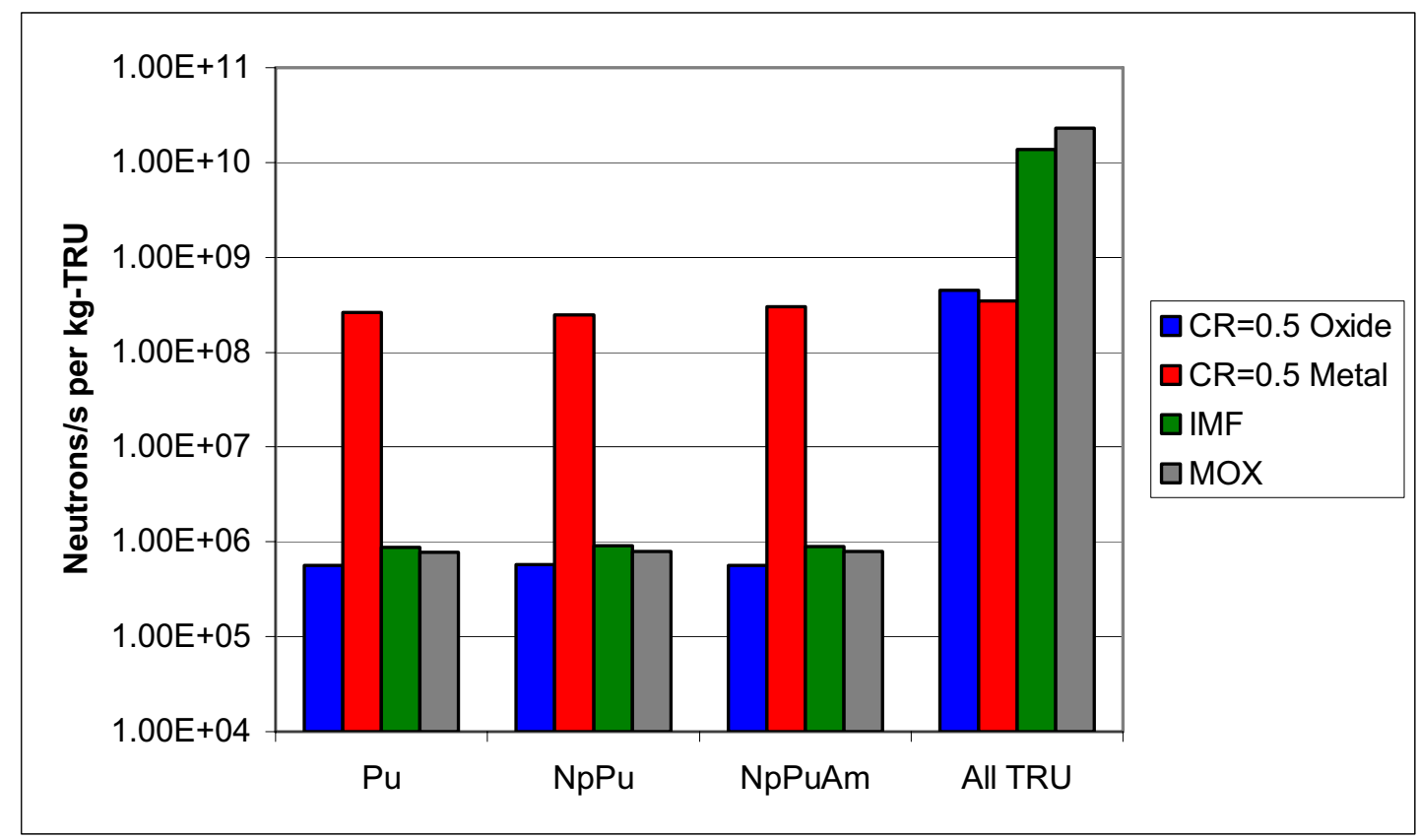

Figure 4-1 Average Charge Gamma Energy for SFR and Thermal Recycling with Multiple Separations Schemes. 


\subsubsection{Gamma Energy Results}

The gamma energy produced by from the fuel charged into the SFR is compared in Figure 4.2 for the same cases as the neutron emission rate. The trends are similar to the neutron emission data in that the additional TRU that is added to the cycle causes the parameter in question to increase. In the case of gamma energy, however, the addition of curium and the higher mass actinides does not have as much of a dramatic effect as in the case of neutron emission. Similarly to the neutron emission, the gamma energy released by the charge fuel remains invariant in the case of the metal fuel SFR charge.

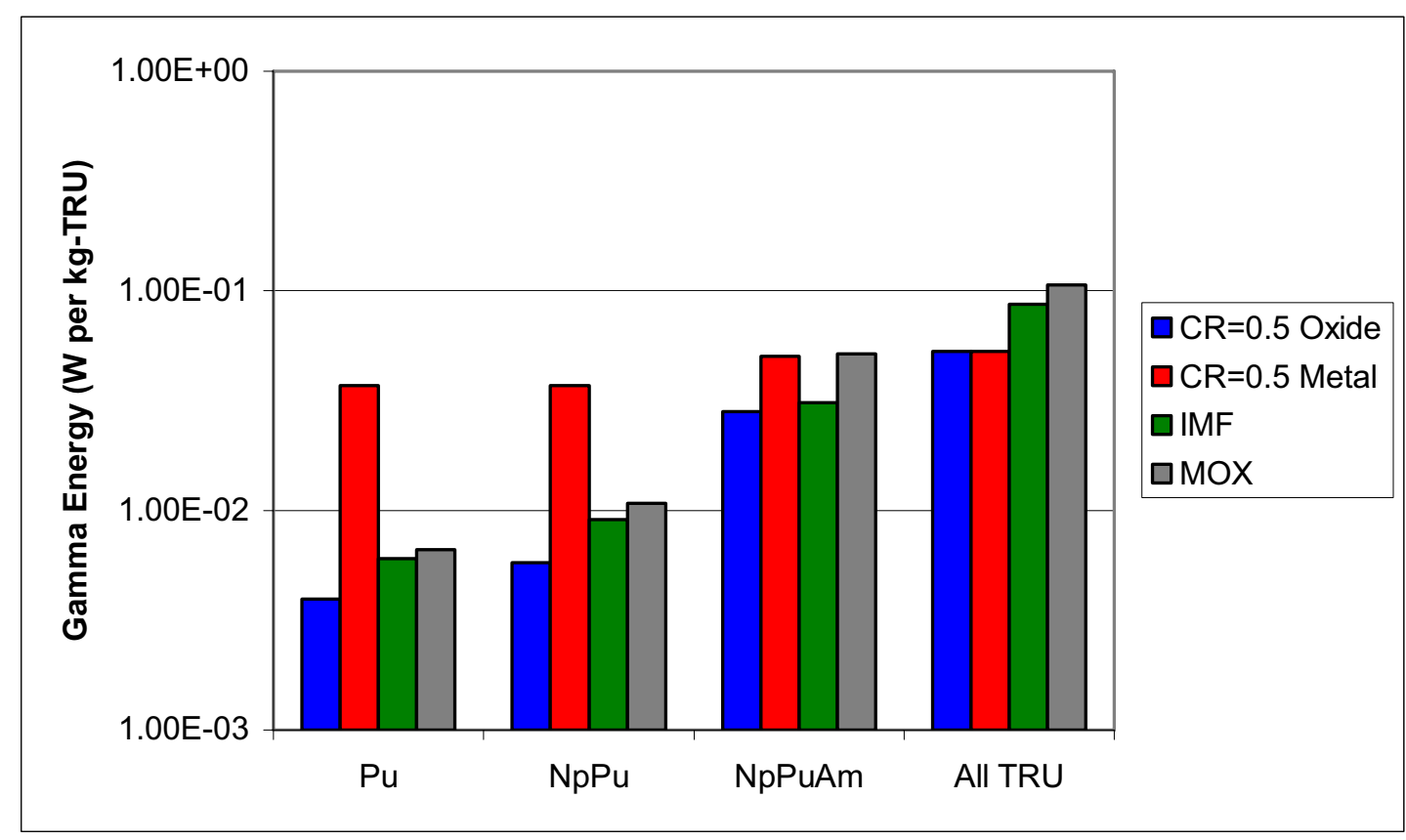

Figure 4-2 Average Charge Gamma Energy for SFR and Thermal Recycling with Multiple Separations Schemes.

\subsubsection{Decay Heat Results}

The decay heat of the reactor discharge for the oxide and metal fuel is compared to thermal IMF and MOX recycling in Figure 4.3. In the case of a metal SFR with electrochemical reprocessing, the charge decay heat remains somewhat invariant to the LWR SNF aqueous-separated isotopic vector. There is only a slight increase when the americium, curium, and higher mass actinides from LWR SNF are included as makeup feed along with the rest of the TRU.

In the case of the oxide fuel SFR the decay heat of the charge increases by going from PUREX all the way to UREX+1a. Similar effects can be seen in thermal MOX and IMF. In the case where all TRU is reprocessed together, thermal IMF has the highest discharge decay heat due to its content of americium, curium, and other actinides. 


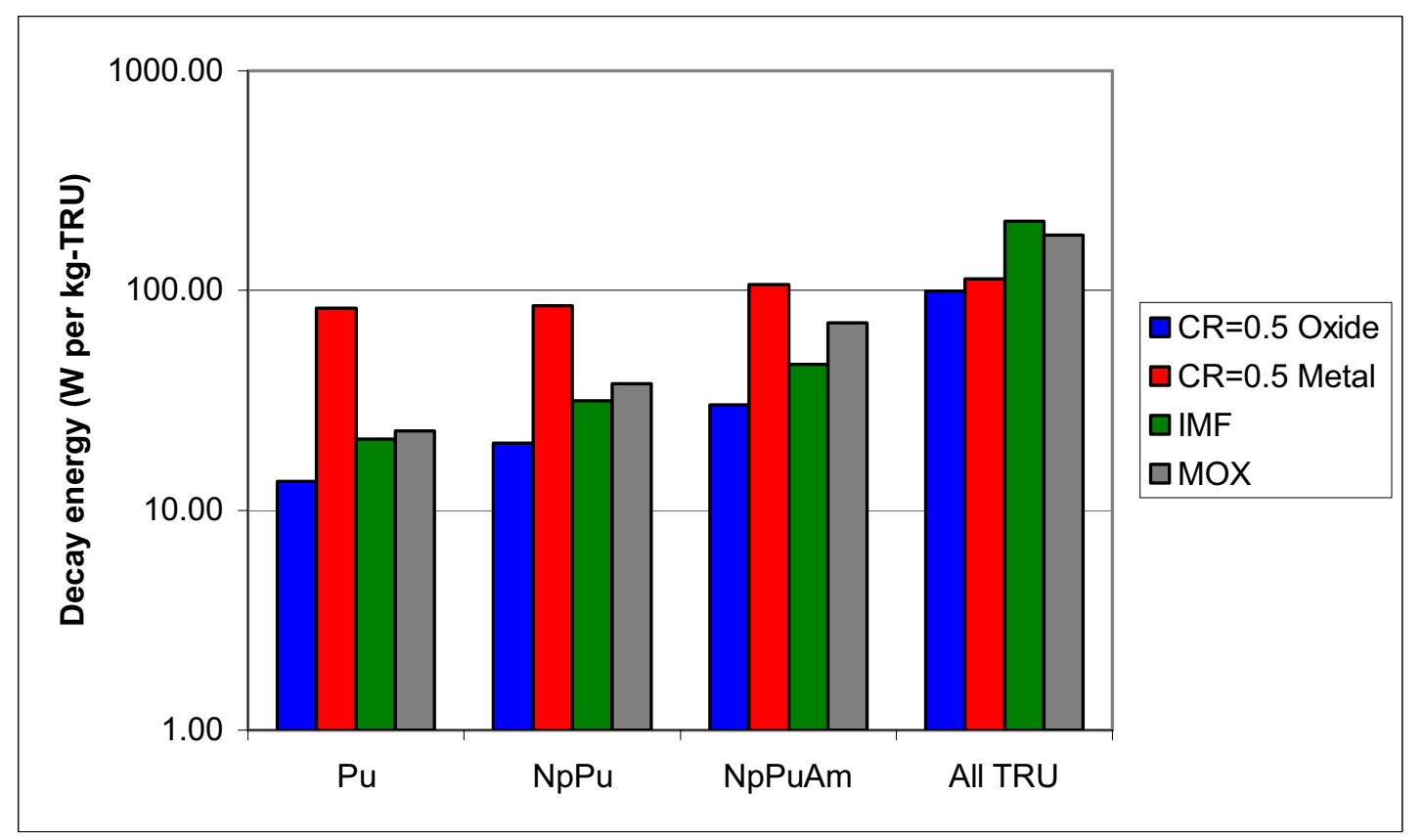

Figure 4-3 Average Charge Decay Heat per kg of TRU For SFR and Thermal Recycling with Multiple Separations Schemes.

An equally important measure of the decay heat is the decay heat per assembly at discharge and beyond. Such data has been tabulated below in Table 4.7. It is evident from the table below that on a per assembly basis the oxide fuel discharge decay heat is higher than metal fuel discharge decay heat. Although the mass density of oxide fuel is smaller than the metal fuel density, the oxide fuel assemblies are larger (35\% taller) and contain a greater volume fraction of fuel $(30.22 \%$ versus $22.08 \%)$ than the metal fuel assemblies.

Table 4-7 Average Charge and Discharge Decay Heat for Metal and Oxide CR=0.50 SFR Design for Multiple Separation Processes.

\begin{tabular}{|c|c|c|c|c|c|c|c|c|c|}
\hline & \multirow{2}{*}{ Cooling Time (years) } & \multicolumn{8}{|c|}{ Maximum Decay Heat (Watts/Subassembly) } \\
\hline & & $\begin{array}{c}\text { Charge } \\
0.00 \\
\end{array}$ & \multicolumn{7}{|c|}{ Discharge } \\
\hline \multirow{2}{*}{ 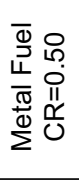 } & PUREX & 306 & 8086 & 5884 & 875 & 366 & 265 & 185 & 165 \\
\hline & UREX+2/+3 & 318 & 8094 & 5892 & 885 & 380 & 280 & 200 & 181 \\
\hline \multirow{4}{*}{ 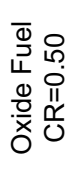 } & PUREX & 82 & 10990 & 7846 & 987 & 341 & 209 & 139 & 130 \\
\hline & UREX+2/+3 & 110 & 11130 & 7952 & 1013 & 365 & 233 & 172 & 164 \\
\hline & UREX+4 & 168 & 11760 & 8600 & 1303 & 542 & 396 & 293 & 269 \\
\hline & UREX+1a & 533 & 11830 & 8665 & 1391 & 649 & 502 & 365 & 327 \\
\hline
\end{tabular}


Table 4-8 Average Charge and Discharge Decay Heat for Metal and Oxide CR=0.50 SFR Design for Multiple 'Vintages' of LWR SNF.

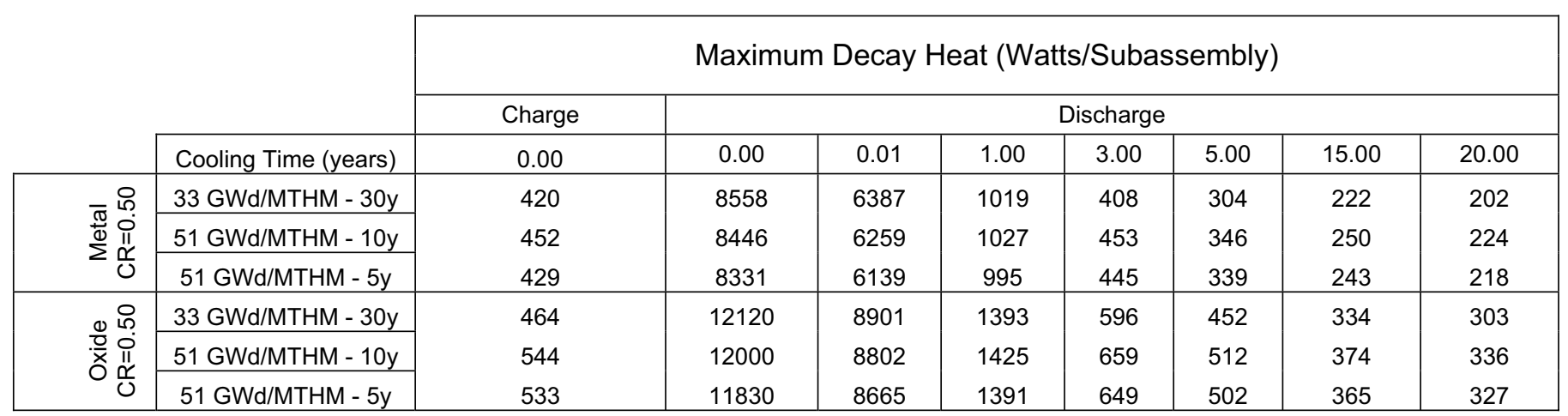

\subsection{Startup Cycles Results}

The initial recycle parameters for the four startup scenarios are summarized in Table 4.9. The cycles operated, as was done previously, under these two limiting parameters: 1) the peak fast fluence is below $4.0 \times 1023 \mathrm{n} / \mathrm{cm}^{2}$ for HT9 cladding and structure, and 2) the displacement per atom of the HT9 cladding is below 200 .

Table 4-9 Cycle Performance Parameters for Startup Cases.

\begin{tabular}{|c|c|c|c|c|c|}
\hline \multirow{2}{*}{\multicolumn{2}{|c|}{ External Feed }} & \multicolumn{4}{|c|}{ Startup Cycle } \\
\hline & & LWR Pu & LWR Np-Pu & WG Pu & Enriched U \\
\hline \multicolumn{2}{|c|}{ Actual Conversion Ratio } & 0.60 & 0.58 & 0.65 & - \\
\hline \multirow{3}{*}{$\begin{array}{l}\text { Charge Enrichment, } \\
\text { TRU/HM (v/f) }\end{array}$} & IC & $21.2 \%$ & $22.0 \%$ & $17.1 \%$ & $23.8 \%$ \\
\hline & MC & $26.5 \%$ & $27.5 \%$ & $21.4 \%$ & $29.8 \%$ \\
\hline & OC & $31.8 \%$ & $33.0 \%$ & $25.7 \%$ & $35.7 \%$ \\
\hline \multirow{3}{*}{$\begin{array}{l}\text { Fuel residence time, } \\
\text { cycles }\end{array}$} & IC & 6 & 6 & 6 & 6 \\
\hline & MC & 6 & 6 & 6 & 6 \\
\hline & OC & 7 & 7 & 7 & 7 \\
\hline Burnup (MWd/kg) & Ave. Driver & 127.1 & 127.1 & 126.0 & 147.6 \\
\hline \multirow{3}{*}{$\begin{array}{l}\text { Peak Fast Fluence, } \\
10^{\star \star} 23 \mathrm{n} / \mathrm{cm}^{\star \star} 2\end{array}$} & IC & 4.00 & 4.00 & 4.00 & 4.00 \\
\hline & MC & 3.91 & 3.90 & 3.90 & 3.84 \\
\hline & OC & 3.63 & 3.62 & 3.62 & 3.53 \\
\hline \multirow{3}{*}{ Maximum DPA } & IC & 183 & 183 & 183 & 183 \\
\hline & MC & 186 & 186 & 186 & 181 \\
\hline & OC & 166 & 166 & 166 & 160 \\
\hline \multicolumn{2}{|c|}{ HM loading, kg } & 9,467 & 9,471 & 9,473 & 9,267 \\
\hline \multicolumn{2}{|c|}{ TRU loading, $\mathrm{kg}$} & 2,384 & 2,486 & 1,914 & - \\
\hline \multicolumn{2}{|c|}{ Fissile $\mathrm{Pu}$ loading, $\mathrm{kg}$} & 1,480 & 1,469 & 1,687 & - \\
\hline \multicolumn{2}{|c|}{ Cycle length, EFPD } & 213 & 213 & 211 & 243 \\
\hline \multicolumn{2}{|c|}{ TRU Consumption Rate, kg/EFPY } & 140.1 & 146.7 & 120.9 & - \\
\hline \multicolumn{2}{|c|}{ TRU Charge, kg/EFPY } & 720 & 750 & 587 & - \\
\hline \multicolumn{2}{|c|}{ HM Charge, kg/EFPY } & 2,784 & 2,782 & 2,808 & 2,414 \\
\hline
\end{tabular}


In all four cases, the $\mathrm{CR}=0.50$ metallic $\mathrm{SFR}$ design was used and the actual conversion ratio was allowed to float. For the enriched uranium case, no TRU conversion ratio was reported since no TRU was initially loaded in the core, which also explains why no values are reported for TRU loading, TRU consumption rate and fissile Pu loading. From Table 4.8, there is very little change between SNF Pu and $\mathrm{SNF} \mathrm{Np}-\mathrm{Pu}$, thus adding the $\mathrm{Np}$ has very little effect on the cycle parameters as was seen previously in Table 4.1. If the external feed becomes weapons grade $\mathrm{Pu}$, the conversion ratio of this core design increases to 0.65 . This increase is caused by the fact that a lower enrichment is needed when compared to the SNF Pu case, thus having a greater fraction of the fuel compose of depleted uranium. If the SFR core is started with enriched uranium, the cycle length and burnup that can be achieved is greater than with the three other cases. 


\section{Conclusions and Future Work}

The purpose of these alternate studies is to understand the effect that different separations, reprocessing methods, and spent nuclear fuel vectors can have on fuel cycle performance and fuel handling parameters for either a metal or oxide SFR design. First, it was found that different separations and reprocessing strategies do not significantly alter the fuel cycle performance parameters such as the TRU enrichment, cycle length, and TRU consumption rate. The small variations that are seen in these parameters are due to changes in the fissile worth of the fuel charge material going into the SFR. For example, applying PUREX process to the external and/or reprocessing feed causes the SFR charge feed to have a higher fissile worth per mass of TRU Thus a lower TRU enrichment is needed for PUREX in comparison to UREX $+1 \mathrm{a}$, where all TRU is recycled back into the SFR. On the other hand, the exclusion of neptunium, americium, curium and higher mass actinides from the TRU charge leaves the question of managing these isotopes unanswered. This leaves the possibility of concentrating these elements in specialized targets that can at least stabilize or greatly reduce their accumulation in the fuel cycle.

The effects of drawing TRU from different LWR SNF vectors were also examined by generating three vectors with different burnup and cooling times. The results show that the TRU feed 'vintage' does not affect the fuel cycle parameters due to similar fissile worth among the three vectors. The slightly larger presence of americium in the low burnup, long cooling time vector increases its own consumption rate in the SFR, and thus increases the production of curium 242 and 244 compared to a high burnup, short cooling time TRU vector.

An important aspect of the reprocessing of metal fuel through electrochemical reprocessing is the reintroduction of americium and curium, while on the other hand the neutron emission, gamma heating, and decay heat for all separation strategies (PUREX, UREX+2/+3, UREX+4, and UREX+1a) remain more or less equal to one another. Thus, no significant reduction in the decay heat, gamma energy, or neutron emission is found by excluding the neptunium, americium, curium, and/or higher mass actinides being separated from LWR SNF and fabricated into metal fuel.

In the case of oxide fuel, the neutron emission, gamma energy, and decay heat were found to decrease when neptunium, americium, curium, and higher mass actinides are separated from the LWR SNF and in the reprocessing and assumed to be disposed of somewhere else. Of course, such a strategy would actually make the SFR produce a net increase in the fuel cycle of these isotopes after each burn cycle.

A potential for these accumulating isotopes in the oxide SFR is to reintroduce them into the reactor in the form of targets. Current efforts involve the investigation of targets in oxide and metallic-fueled SFR as once-through or continual reprocessing. 


\section{References}

1. D. C. WADE, R. N. HILL, "The Design Rationale of the IFR," Progress in Nuclear Energy, 31, 1-2, 13-42 (1997).

2. R. A. WIGELAND and T. H. BAUER, "Repository Benefits of AFCI Options," Argonne National Laboratory, ANL-AFCI-129, September (2004).

3. A. E. DUBBERLEY, K. YOSHIDA, C. E. BOARMAN, and T. WU, "SuperPRISM Oxide and Metal Fuel Core Designs," Proc. of ICONE 8, $8^{\text {th }}$ International Conference on Nuclear Engineering (2000).

4. R. N. HILL, D. C. WADE, E. K. FUJITA, and H. KHALIL, "Physics Studies of Higher Actinide Consumption in an LMR," Proc. Int. Conf. on the Physics of Reactors, Marseille, France, p.I-83, April 23-27 (1990).

5. R. N. HILL, D. C. WADE, J. R. LIAW, and E. K. FUJITA, "Physics Studies of Weapons Plutonium Disposition in the Integral Fast Reactor Closed Fuel Cycle," Nuclear Science and Engineering, 121, 17 (1995).

6. E. A. HOFFMAN, W. S. YANG, and R. N. HILL, "Preliminary Core Design Studies for the Advanced Burner Reactor over a Wide Range of Conversion Ratios," Argonne National Laboratory, ANL-AFCI-177 (2006).

7. M. A. SMITH, E. E. MORRIS, R. N. HILL, "Physics and Safety Studies of Low Conversion Ratio Sodium Cooled Fast Reactors", Global 2003, New Orleans, Louisiana, United States, pp. 423-433, November 16-20 (2003).

8. H. HENRYSON II, B. J. TOPPEL, and C. G. STENBERG, "MC' 2 -2: A Code to Calculate Fast Neutron Spectra and Multi-Group Cross-Sections." ANL-8144, Argonne National Laboratory (1976).

9. B. J. Toppel, "A User's Guide to the REBUS-3 Fuel Cycle Analysis Capability," ANL-83-2, Argonne National Laboratory (1983).

10. C. E. LAHM, J. F. KOENIG, R. G. PAHL, D. L. PORTER, and D. C. CRAWFORD, "Experience with Advanced Driver Fuels in EBR-II," Journal of Nuclear Materials, 204, 119 (1993).

11. R. B. BAKER, F. E. BARD, R. D. LEGGETT, and A. L. PINTER, "Status of Fuel, Blanket, and Absorber Testing in the Fast Flux Test Facility," Journal of Nuclear Materials, 204, 109 (1993).

12. A. L. PINTER and R. B. BAKER, "Metal Fuel Test Program in the FFTF," Journal of Nuclear Materials, 204, 124 (1993).

13. R. E. MACFARLANE and D. W. MUIR, "The NJOY Nuclear Data Processing System Version 91,” LA-12740-M, October 1994. Available from Radiation Safety Information Computational Center at Oak Ridge National Laboratory as P00-368. 
14. SCALE: A Modular Code System for Performing Standardized Computer Analyses for Licensing Evaluation, ORNL/TM-2005/39, Version 5.1, Vols. I-III, November 2006. Available from Radiation Safety Information Computational Center at Oak Ridge National Laboratory as C00732.

15. TRITON: A Two-Dimensional Transport and Depletion Module for Characterization of Spent Nuclear Fuel, ORNL/TM-2005/39, Revision 5.1, Vol. I, Book 3, Sect. T1, November 2006. Available from Radiation Safety Information Computational Center at Oak Ridge National Laboratory as C00-732.

16. ORIGEN-S: Scale System Module to Calculate Fuel Depletion, Actinide Transmutation, Fission Product Buildup and Decay, and Associated Radiation Source Terms, ORNL/TM-2005/39, Revision 5.1, Vol. II, Book 1, Sect. F7, November 2006. Available from Radiation Safety Information Computational Center at Oak Ridge National Laboratory as C00-732.

17. B. FORGET, M. ASGARI, R. M. FERRER, and S. BAYS, "Importance of the (n,gamma) Cm247 Evaluation on Neutron Emission in Fast Reactor Fuel Cycle Analysis," Trans. Am. Nucl. Soc., TO BE PUBLISHED (2007). 